Florida International University FIU Digital Commons

$11-12-2015$

\title{
Gaseous Carbon Emissions (Methane and Carbon Dioxide) from Wetland Soils in a Re-created Everglades Landscape
}

Bradley R. Schonhoff

Florida International University, bscho011@fiu.edu

DOI: $10.25148 /$ etd.FIDC000188

Follow this and additional works at: https:// digitalcommons.fiu.edu/etd

Part of the Biogeochemistry Commons, Hydrology Commons, Soil Science Commons, and the Water Resource Management Commons

\section{Recommended Citation}

Schonhoff, Bradley R., "Gaseous Carbon Emissions (Methane and Carbon Dioxide) from Wetland Soils in a Re-created Everglades Landscape" (2015). FIU Electronic Theses and Dissertations. 2289.

https://digitalcommons.fiu.edu/etd/2289 


\title{
FLORIDA INTERNATIONAL UNIVERSITY
}

Miami, Florida

\section{GASEOUS CARBON EMISSIONS (METHANE AND CARBON DIOXIDE) FROM WETLAND SOILS IN A RE-CREATED EVERGLADES LANDSCAPE}

\author{
A thesis submitted in partial fulfillment of the \\ requirements for the degree of \\ MASTER OF SCIENCE \\ in \\ ENVIRONMENTAL STUDIES \\ by
}

Bradley R. Schonhoff

2015 
To: Dean Michael R. Heithaus

College of Arts and Sciences

This thesis, written by Bradley R. Schonhoff and entitled Gaseous Carbon Emissions (Methane and Carbon Dioxide) from Wetland Soils in a Re-created Everglades Landscape, having been approved in respect to style and intellectual content, is referred to you for judgment.

We have read this thesis and recommend that it be approved.

$\begin{array}{r}\hline \text { René M. Price } \\ \hline \text { John S. Kominoski } \\ \hline \text { Thomas W. Dreschel } \\ \hline \text { Leonard J. Scinto, Major Professor }\end{array}$

Date of Defense: November 12, 2015.

The thesis of Bradley R. Schonhoff is approved.

$\begin{array}{r}\hline \begin{array}{c}\text { Dean Michael R. Heithaus } \\ \text { College of Arts and Sciences }\end{array} \\ \hline \begin{array}{r}\text { Dean Lakshmi N. Reddi } \\ \text { University Graduate School }\end{array}\end{array}$

Florida International University, 2015 


\section{ACKNOWLEDGMENTS}

I would first like to express my sincerest gratitude to Dr. Len Scinto for allowing me, an obvious newcomer to the field, an opportunity to come to Florida to "do" science. He insisted early on that I didn't really want to study what interested me when I first arrived here, and thankfully, he was right in the end. His guidance and support at every step gave me a chance to follow through with a project that posed a special challenge for me, and that challenge has made a world of difference. The main counterpart in my education came from the scientific research team at the Loxahatchee Impoundment Landscape Assessment, and especially from Eric Cline, to whom I owe a great deal. His steady demeanor was an exceptional model for how to lead and collaborate with others; through respect, integrity, and humor.

I would also like to thank Diana Johnson of the Freshwater Biogeochemistry Laboratory at FIU, and Alexandra Serna of the Southeast Environmental Research Center, whose active teaching and assistance gave me the tools and experience needed to complete this project. Many thanks to Dr. Tom Dreschel for constantly lending his experience and advice, and to each of my committee members, including Drs. René Price and John Kominoski, for their patience and support.

Finally, a special thanks to my personal support team: my family and friends, whose unconditional support and encouragement gave me the confidence to not only start along this new and unfamiliar path, but to see it through as well. You are all very important, and very much appreciated. 


\begin{abstract}
OF THE THESIS
GASEOUS CARBON EMISSIONS (METHANE AND CARBON DIOXIDE) FROM

WETLAND SOILS IN A RE-CREATED EVERGLADES LANDSCAPE
\end{abstract}

by

Bradley R. Schonhoff

Florida International University, 2015

Miami, Florida

Professor Leonard J. Scinto, Major Professor

Reducing the rates of greenhouse gas (GHG) emissions is critical in combatting global climate change. Carbon dioxide $\left(\mathrm{CO}_{2}\right)$ and methane $\left(\mathrm{CH}_{4}\right)$ are the two most important carbon-based GHGs, for their atmospheric warming potential. Wetlands such as the Florida Everglades play major roles in the global carbon cycle, as varying hydrologic conditions lead to differential production rates of these two GHGs. This study measured $\mathrm{CO}_{2}$ and $\mathrm{CH}_{4}$ emissions in a re-created Everglades ridge-and-slough wetland, where water levels were controlled to reflect natural flood patterns. As expected, lower elevations were flooded longer and produced more $\mathrm{CH}_{4}$, while higher elevations produced more $\mathrm{CO}_{2}$. Since $\mathrm{CH}_{4}$ has a relatively high global warming potential, $\mathrm{CO}_{2}$ production would need to be 70 times that of $\mathrm{CH}_{4}$, to balance their GHG output. The average ratio of $\mathrm{CO}_{2}$ to $\mathrm{CH}_{4}$ across elevations was 22.0 (mol:mol), indicating that future water management within wetlands should consider GHG production potential. 
CHAPTER

PAGE

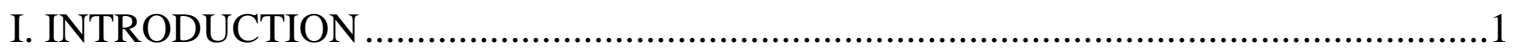

II. BACKGROUND

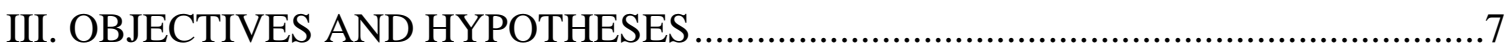

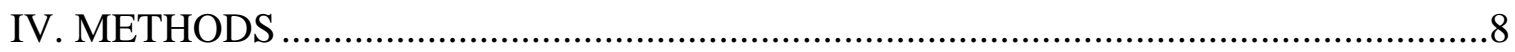

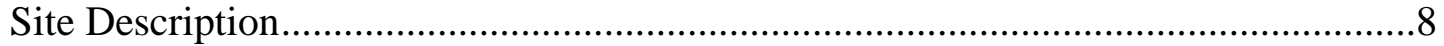

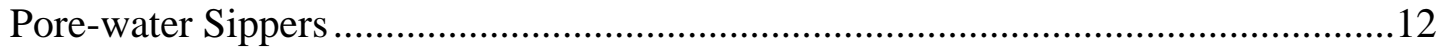

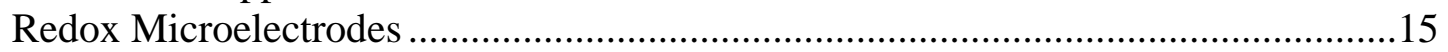

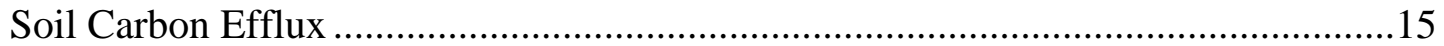

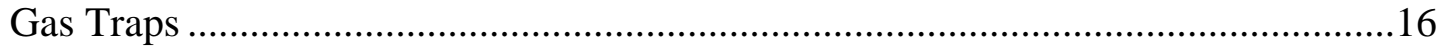

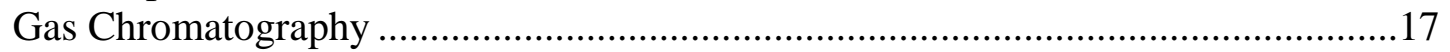

Statistical Analyses ............................................................................................

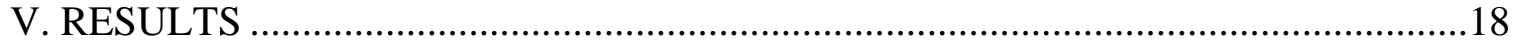

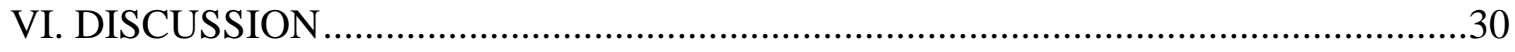

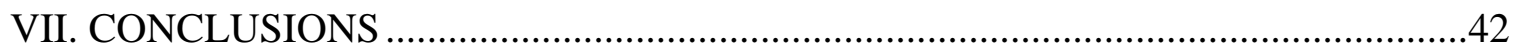

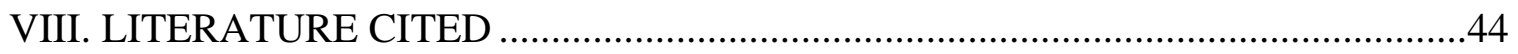

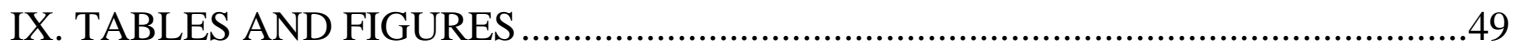




\section{LIST OF TABLES}

TABLE

PAGE

1. Global Warming Potential (GWP) of prevalent greenhouse gases (GHGs) in the atmosphere, including $\mathrm{CO}_{2}$ and $\mathrm{CH}_{4}$, with $\mathrm{CO}_{2}$ used as a baseline...............................49

2. Descriptive results from ANOVAs of pore-water sipper data in M4 ........................60

3. Descriptive results from ANOVAs of pore-water sipper data taken in M1 ...............61

4. Correlations of variables in M4 from September 2014 to June 2015 .66

5. Correlations for M1 variables during a hydrologic reversal from April 2015 until June 2015 


\section{LIST OF FIGURES}

FIGURE

PAGE

1. Changes in atmospheric concentrations of $\mathrm{CO}_{2}$ and $\mathrm{CH}_{4}$ (from ice core data), with dramatic increases coinciding with recent industrial activity

2. LILA macrocosms and constructed landscape components of varying elevations, modified from Aich et al., 2011.

3. Operational hydrograph at LILA, with elevations given in standardized ft NGVD (National Geodetic Vertical Datum). Stage (water level) is controlled and adjusted biweekly in each individual macrocosm according to historical seasonal averages, represented by the green line. Other experimental hydrographs include controls for flood conditions (blue line) and below-seasonal levels (red line). During the summer 2015, water levels dropped below these lower standards, falling into a Drought category

4. LILA M4 hydrograph from July 2014 until June 2015, including six sampling iterations, from September 2014 until May 2015. Elevation is given in feet NGVD, including relative elevations of all sites featured in M4: Tree Island Head High (HH) at $16.5 \mathrm{ft}$ NGVD, Tree Island Head Low (HL) at $15 \mathrm{ft}$ NGVD, Middle Ridge (MR)

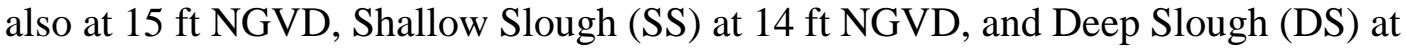
$13.5 \mathrm{ft}$ NGVD.

5. LILA hydrograph for M4 and M1, from July 2014 until June 2015. Elevations are given in $\mathrm{ft}$ NGVD. All stage values came from the South Florida Water Management District's (SFWMD) DBHYDRO database, and were quality-assured and qualitycontrolled (QAQC) by SFWMD in July 2015. Water levels were planned to be raised in June 2015, but an atypical drought in summer of 2015 prevented enough water from being available to increase stages according to the operational hydrograph

6. LILA M1 hydrograph from March 2015 until June 2015, including six sampling iterations, from April 2015 to May 2015. Data collection was scheduled to include sampling during periods that were hydrologically-similar to those used in M4: preflooding, mid-flood, at-peak levels, mid-recession, and post-recession. Elevation is given in feet NGVD, and includes relative elevations of all sites featured in M1 (constructed at equal elevations to those in M4)

7. Efflux rates of $\mathrm{CO}_{2}$ across relative water depth, shown in a previous LILA study (Schroeder, 2012) 
8. Relative elevations of constructed landscape features within a LILA macrocosm, including approximate depictions of sipper tubes installed throughout each site at varying depths. To compare relative depths, the soil surface of the deep slough (DS) was set as a baseline elevation, with other depths compared relative to this low point ....57

9. Photo of LICOR LI-8100 IRGA sampling above flooded soils, with installed porewater sipper tubes also featured to the left of the floating platform and IRGA..................58

10. Photo of a Gas Trap installed within a shallow slough in M4 .59

11. Boxplot of $\mathrm{CH}_{4}$ concentrations in $\mathrm{mmol} \mathrm{L}^{-1}$ taken from pore-water sippers installed in M4 across all sites: Tree Island Head High (HH), Tree Island Head Low (HL), Middle Ridge (MR), Shallow Slough (SS), and Deep Slough (DS), listed leftto-right from highest to lowest site elevation (except for the HL and MR sites which are situated at the same elevation). Circles outside of box-and-whisker plots represent outliers, while stars represent extreme outliers.

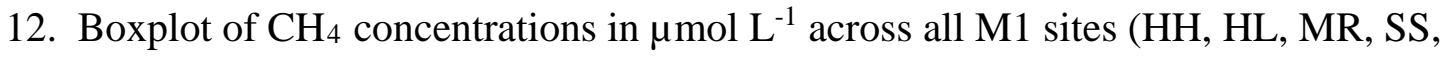
and DS), listed left-to-right from highest to lowest site elevation (except for HL and MR). Circles outside of plots represent outliers, and stars represent extreme outliers....

13. Boxplot of $\mathrm{CO}_{2}$ concentrations in mmol $\mathrm{L}^{-1}$ from pore-water sippers in $\mathrm{M} 4$ across all sites (HH, HL, MR, SS, DS), which are listed left-to-right from highest to lowest site elevation (except for HL and MR sites which are situated at the same elevation). Circles outside of box-and-whisker plots represent outliers, and stars represent extreme outliers

14. Boxplot of $\mathrm{CO}_{2}$ concentrations in mmol $\mathrm{L}^{-1}$ across $\mathrm{M} 1$ sites (HH, HL, MR, SS, DS), listed left-to-right from highest to lowest site elevation (except for HL and MR). Circles outside plots represent outliers, and stars represent extreme outliers.

15. Boxplot of $\mathrm{CO}_{2} / \mathrm{CH}_{4}$ ratios (mol:mol) taken from pore-water data in $\mathrm{M} 4$ across all sites (HH, HL, MR, SS, and DS), and listed left-to-right from highest to lowest site elevation (except for the HL and MR sites at the same elevation). Circles outside of box-and-whisker plots represent outliers, while stars represent extreme outliers

16. Boxplot of $\mathrm{CO}_{2} / \mathrm{CH}_{4}$ ratios from sipper data across all sites in $\mathrm{M} 1 \mathrm{HH}, \mathrm{HL}, \mathrm{MR}$, SS, DS), listed left-to-right from highest to lowest site elevation (except for HL and MR). Circles outside plots represent outliers, stars represent extreme outliers.

17. Average LICOR $\mathrm{CO}_{2}$ efflux rates $\left(\mathrm{mol} \mathrm{m}^{2} \mathrm{~s}^{-1}\right)$ across all sites in $\mathrm{M} 4(\mathrm{HH}, \mathrm{HL}$, MR, SS, DS), with stage values given in ft NGVD, from September 2014 until May 2015 
18. Average LICOR $\mathrm{CO}_{2}$ efflux rates, in $\mathrm{mol} \mathrm{m}^{2} \mathrm{~s}^{-1}$, during $\mathrm{M} 1$ reversal from April 2015 until June 2015, with stage values also given in feet NGVD ……………................71

19. All gas trap data taken from all sites in both macrocosms, from September 2014 until June 2015, with $\mathrm{CH}_{4}$ and $\mathrm{CO}_{2}$ concentrations given in $\mathrm{mmol} \mathrm{L}^{-1}$

20. Gas trap data taken from slough sites (DS and SS) in M4, from October 2014 until June 2015, with concentrations of $\mathrm{CH}_{4}$ and $\mathrm{CO}_{2}$ given in $\mathrm{mmol} \mathrm{L}^{-1}$...... .73 


\section{ABBREVIATIONS AND ACRONYMS}

\begin{tabular}{|c|c|}
\hline $\mathrm{CH}_{4}$ & Methane \\
\hline $\mathrm{CO}_{2}$ & Carbon Dioxide \\
\hline DS & Deep Slough \\
\hline GC & Gas Chromatograph \\
\hline GHG & Greenhouse Gas \\
\hline GWP & Global Warming Potential \\
\hline $\mathrm{HH}$ & Tree Island, Head High \\
\hline HL & Tree Island, Head Low \\
\hline IRGA & Infrared Gas Analyzer \\
\hline LILA & Loxahatchee Impoundment Landscape Assessment \\
\hline M1 & Macrocosm 1 \\
\hline M4 & Macrocosm 4 \\
\hline MR & Middle Ridge \\
\hline NGVD & National Geodetic Vertical Datum \\
\hline SFWMD & South Florida Water Management District \\
\hline SS & Shallow Slough \\
\hline
\end{tabular}




\section{INTRODUCTION}

There is widespread consensus among scientists today that global climate change represents the single greatest environmental issue of our relatively short human history (Kolbert, 2011). Climate change is mainly driven by greenhouse gas (GHG) emissions, which have increased along with human consumptions of carbon-based, non-renewable energies: coal, oil, and natural gas. As GHGs are released from the burning of these fuels, they trap solar radiation within the atmosphere and have a general warming effect on the planet (Kennedy et al., 2006). In terms of overall climate impact, the two most important characteristics of a GHG are: how well the gas absorbs energy, and how long it remains in the atmosphere (US EPA, 2014). As a result of increasingly high atmospheric concentrations, carbon dioxide $\left(\mathrm{CO}_{2}\right)$ is generally viewed as the most important GHG today. Methane $\left(\mathrm{CH}_{4}\right)$, another carbon-based GHG, is largely considered to be the next most important GHG for its ability to have a greater warming effect in similar quantities.

Table 1 displays the global warming potential (GWP) for some of the most prevalent greenhouse gases in our atmosphere, and illustrates that over short-term spans of twenty years, the effect of $\mathrm{CH}_{4}$ in our atmosphere is about 72 times more effective than $\mathrm{CO}_{2}$, on a mole-to-mole basis. The effect decreases over time, but even after hundreds of years, $\mathrm{CH}_{4}$ can still be several times more effective as a warming agent than $\mathrm{CO}_{2}$. In terms of GWP, $\mathrm{CO}_{2}$ is used as a baseline, since its GWP remains relatively constant over 20, 100, and 500-year timescales (Table 1). The lifetime of these GHGs is also given, as the average timeframe that each type of gas may remain in our atmosphere. 
The lifetime of $\mathrm{CH}_{4}$ (12 years) is relatively short compared to that of $\mathrm{CO}_{2}$, which can persist within the atmosphere for much longer periods - hundreds to even thousands of years - before eventually being broken down or reabsorbed into other biogeochemical systems. Because of its relative GWP, releases of $\mathrm{CH}_{4}$ could have a greater impact on our atmosphere than even larger amounts of $\mathrm{CO}_{2}$. In addition to its disproportionate warming potential, atmospheric $\mathrm{CH}_{4}$ often oxidizes to become $\mathrm{CO}_{2}$, prolonging the effect as a warming agent. All of this illustrates a few key reasons why $\mathrm{CH}_{4}$ should be prioritized alongside $\mathrm{CO}_{2}$ for efforts related to GHG emissions reductions (Ma et al., 2012).

The link between industrialization and other anthropogenic (human-caused) activities and GHG emissions seems clear, as a rise in atmospheric GHG concentrations has coincided with the recent increase in fossil fuel use since the Industrial Revolution (Figure 1). The effects of rising atmospheric concentrations are compounded by human damage to many carbon "sinks" - ecosystems that absorb significant amounts of carbon from the atmosphere - via deforestation and the destruction of wetlands. The Everglades serves as a prime example: Over the last 130 years, land development and agriculture have severely altered the hydrologic regime of the system, to the extent that approximately half of the original Everglades area has been impacted by $2500 \mathrm{~km}$ of spillways, levees, canals, and water control structures that were designed for flood protection, and providing water to many areas of Florida that lie south of Lake Okeechobee (Wu et al., 2006; Light and Dineen, 1994; USACE and SFWMD, 1999). In response to massive reductions in the amount and flow of water throughout South Florida, restoration efforts have included the systematic re-flooding of some of these drained 
areas. Although these activities may be intended to reestablish the natural water regime, rewetting these soils can have unintended, negative consequences. Namely, it can result in the release of gaseous $\mathrm{CH}_{4}$ from wetland peat soils into the atmosphere, thereby increasing and/or accelerating the overall warming effect.

\section{BACKGROUND}

The Florida Everglades is characterized by a few key landscape components: tree islands, ridges, and sloughs, which follow a landscape pattern running parallel to the direction of water flow (McVoy et al., 2011). The distinction between these different components is largely determined by relative levels of elevation. At the highest points, tree islands punctuate the landscape at around $1 \mathrm{~m}$ above the surrounding slough surface, providing dry habitat for wildlife and vegetation (Larsen et al., 2011; Gawlik et al., 2002). At slightly lower elevations, partially-flooded ridges are distinguishable by the tall sawgrass (Cladium jamaicense Crantz) that dominates their surfaces (Watts et al., 2010). Finally, deeper sloughs are like the rivers of these ecosystems, containing periphyton and white water lily (Nymphea oderata Aiton). Although the differences in relative elevation between these landscape features can be very subtle, the resulting changes in flood patterns can greatly affect the balance of carbon.

As some of the most productive ecosystems on the planet, wetlands are now recognized as key components of the global carbon cycle, for their potential as both carbon sinks and sources (Schedlbauer et al., 2012). The total global wetland area is 
estimated to be between 5-8\% of Earth’s land surface (Houghton \& Skole, 1990). Of these areas, any that contain a significant accumulation of organic, nutrient-rich peat soils are generally termed "peatlands.” Peatlands may only account for less than half of the total global wetland area (about 3\% of Earth’s land surface), but they are nonetheless important for carbon sequestration (Gorham, 1991; Siegel et al., 1994). Globally, more carbon is stored in soil than in the atmosphere and plant biomass (living and dead) combined, and peatlands are estimated to contain about a third of global soil carbon deposits (Reddy \& DeLaune, 2008). Peatlands are also estimated to account for 5-10\% of global $\mathrm{CH}_{4}$ emissions, while simultaneously acting as a net sink for atmospheric $\mathrm{CO}_{2}$ (Siegel et al., 1994; Charman, 2002). Further research needs to be conducted to provide a deeper understanding of this unique balance of $\mathrm{CO}_{2}$ and $\mathrm{CH}_{4}$ as part of the carbon budget, and the mechanisms behind the overall GHG production by wetlands.

Hydrology plays a major role in determining the carbon budget of wetlands, as changing water levels drive the release and uptake of $\mathrm{CO}_{2}$ and $\mathrm{CH}_{4}$ (Smith et al., 2003; Webster et al., 2013). Recent studies within the Everglades show that rates of carbon exchange in both short- and long-hydroperiod systems are highly sensitive to seasonality and the extent of flooding (Schedlbauer et al., 2012; Webster et al., 2013). As water levels drop below the soil surface, freely-available oxygen initiates decomposition, which results in higher rates of $\mathrm{CO}_{2}$ emissions into the atmosphere (Webster et al., 2013). Although inundated conditions conversely promote carbon storage by stalling decomposition and reducing $\mathrm{CO}_{2}$ emissions, extended periods of flooding can create an 
additional source of gaseous carbon by greatly increasing rates of $\mathrm{CH}_{4}$ production (Malone et al., 2013; Smith et al., 2003; Webster et al., 2013).

Flooded areas such as wetlands represent a global source of $\mathrm{CH}_{4}$, because of the process of methanogenesis $\left(\mathrm{CH}_{4}\right.$ production) that occurs under anaerobic (low-oxygen) soil conditions. During dry periods, the water table lies below the soil surface and soils are therefore at least partially dry, allowing pore spaces within the soil matrix to become aerated. During periods of inundation, however, water fills these empty spaces, and the diffusion of oxygen is reduced by about 10,000 times (Mitsch and Gosselink, 2007). Under anaerobic conditions, oxidation and decomposition persist as long as there are alternative electron acceptors to aid the process. When the primary source of oxidation (oxygen) is unavailable because soils are submerged, other electron acceptors (nitrates, manganese and iron oxides, sulfates, and $\mathrm{CO}_{2}$ ) are utilized in fixed succession to promote further decomposition (Reddy \& DeLaune, 2008). Once all of the alternative electron acceptors have been exhausted, the use of $\mathrm{CO}_{2}$ by microbial communities can ultimately stimulate methanogenesis, as specially-adapted anaerobic microbes break down organic carbon materials and produce $\mathrm{CH}_{4}$ as a byproduct (Laanbroek, 2010). The release of $\mathrm{CH}_{4}$ into the atmosphere tends to be occur via ebullition (sporadic bubbling), since $\mathrm{CH}_{4}$ is relatively insoluble in water (Reddy \& DeLaune, 2008).

Because $\mathrm{CH}_{4}$ has a high GWP compared to $\mathrm{CO}_{2}$, and since $\mathrm{CH}_{4}$ production is tied to flooding, the frequency and duration of higher water levels may be the keys to determining whether a particular wetland system acts as a net sink or source of carbon 
(Malone et al., 2013). Recent studies have suggested that despite the characteristic differences between the three main Everglades landscape features (tree islands, ridges, and sloughs), each may possesses a significant potential for $\mathrm{CH}_{4}$ production, especially after prolonged flooding. Regardless of the hydrologic patterns at these locations, they each contain the microbes responsible for methanogenisis within their soils (Kannenberg et al., 2015). However, an analysis of the differences in relative potential for $\mathrm{CH}_{4}$ and $\mathrm{CO}_{2}$ across these landscape features remains incomplete. As the climate profile of our planet undergoes significant changes, the duration of drought and precipitation cycles will have a major impact on the ability of wetlands such as the Everglades to act as either net sources or sinks of these important GHGs (Malone et al., 2013).

If global climate change continues along similar trajectories, conditions will only continue to promote GHG emissions from wetlands. Increasing temperatures will cause wetlands to experience longer droughts, which will expose soils to oxygen and release $\mathrm{CO}_{2}$. As restoration efforts attempt to rewet previously-drained areas, increased flooding may lead to $\mathrm{CH}_{4}$ production, resulting in greater overall GHG emissions. As a result, wetland systems could act as a source of GHGs in both seasons, under wet and dry conditions. This situation holds global implications, as climate change and sea level rise pose significant threats to the integrity of our coastal and wetland environments, as well as the people and wildlife that fundamentally depend on these ecosystems. It therefore remains crucial to gain a better understanding of the dynamic wetland carbon balance; in order to better manage flooding throughout these systems, or alternatively strive to promote conditions that will have the least overall impact on the environment. 


\section{OBJECTIVES AND HYPOTHESES}

Given the knowledge gaps related to this subject, there are a few main objectives for this study. Firstly, to quantify emission rates for two primary GHGs involved in wetland carbon budgets $-\mathrm{CH}_{4}$ and $\mathrm{CO}_{2}$ - under both wet and dry conditions in a re-created, peatbased Everglades wetland with varying topographic features. Next, to determine the effects of varying water levels and elevation on overall $\mathrm{CH}_{4}$ and $\mathrm{CO}_{2}$ emission rates. Finally, to compare $\mathrm{CO}_{2} / \mathrm{CH}_{4}$ emission ratios across the five main Everglades landscape components: tree island head high, tree island head low, middle ridge, shallow slough, and deep slough. A better understanding of these factors will help to develop a clearer profile of the balance of GHG production across various features within wetland landscapes such as the Everglades.

Since hydrology plays a lead role in driving the biogeochemistry of wetland systems, higher water levels and prolonged flooding are hypothesized to correspond with increased rates of $\mathrm{CH}_{4}$ production, as anaerobic conditions lead to methanogenesis. Areas of lower elevation, and therefore higher water levels sustained over longer periods, are therefore hypothesized to exhibit the highest overall concentrations of $\mathrm{CH}_{4}$. Conversely, increased $\mathrm{CO}_{2}$ concentrations are expected to occur at the highest elevations; those areas which remain dry year-round or experience only temporary flooding before being reexposed. Additionally, ratios of $\mathrm{CO}_{2} / \mathrm{CH}_{4}$ are likewise predicted to be greatest in the zones of highest elevation, where $\mathrm{CO}_{2}$ concentrations are expected to be the highest and $\mathrm{CH}_{4}$ concentrations the lowest. 


\section{METHODS}

The Florida Everglades is characterized by a few key landscape components: tree islands, ridges, and sloughs, which follow a landscape pattern running parallel to the direction of water flow (McVoy et al., 2011). The distinction between these different components is largely determined by relative levels of elevation. At the highest points, tree islands punctuate the landscape at around $1 \mathrm{~m}$ above the surrounding slough surface, providing dry habitat for wildlife and vegetation (Larsen et al., 2011; Gawlik et al., 2002). At slightly lower elevations, partially-flooded ridges are distinguishable by the tall sawgrass (Cladium jamaicense Crantz) that dominates their surfaces (Watts et al., 2010). Finally, deeper sloughs are like the rivers of these ecosystems, containing periphyton and white water lily (Nymphea oderata Aiton). Although the differences in relative elevation between these landscape features can be very subtle, the resulting changes in flood patterns can greatly affect the balance of carbon.

\section{Site Description}

This study was conducted at the Loxahatchee Impoundment Landscape Assessment (LILA), located at the Arthur R. Marshall Loxahatchee National Wildlife Refuge, in Boynton Beach, Florida. The overall experimental area has been divided into four 8.1-hectare “macrocosms,” with each macrocosm containing a set of constructed landscape features (tree islands, ridges, and both deep and shallow sloughs) that simulate ecosystem components of the greater Everglades (Aich et al., 2011; Stofella et al., 2010). This particular experiment took place in the northernmost and southernmost macrocosms, 
involving the area within and surrounding the western tree islands, labeled M1W and M4W (Figure 2). Within these peat-based macrocosms, a total of five landscape components were studied, which are characteristic of the varying topography and elevation of the greater Everglades: tree island head, high elevations $(\mathrm{HH})$; tree island head, low elevations (HL); middle ridge (MR); shallow slough (SS); and deep slough (DS). The hydrology of LILA is maintained by a large electric pump (1.84 $\left.\mathrm{m}^{3} \mathrm{~s}^{-1}\right)$, a series of water control structures, and gauges that record stage (water level), all of which allows monitoring and management of both water levels and flow rates within each individual macrocosm (Stofella et al., 2010). LILA serves as a physical model of the Everglades and enables investigators to measure environmental responses to restoration strategies, as hydrology and other processes are simulated and controlled.

Water levels in each of the cells at LILA are managed according to an operational hydrograph derived from historical seasonal averages for the Everglades (Figure 3). The highest water levels occur from September to January, and lowest from April to June. This experiment primarily focused on M4, which was deemed the best macrocosm for the study since it was the first macrocosm constructed at LILA using Loxahatchee peat soils, and contains the greatest buildup of peat soil. The western tree islands in M4 and M1 were also developed on top of a peat-based core, as opposed to others which were built on limestone cores. Sampling occurred in M4 from September 2014 until May 2015 (Figure 4). To study the influence of flooding on $\mathrm{CO}_{2}$ and $\mathrm{CH}_{4}$ production, samples were collected at several points throughout the course of a wetting and drying cycle. A total of six sampling iterations were conducted, to record measurements during various stages of 
the hydrograph. Five main iterations included: pre-flooding, mid-flood, at-peak levels, mid-recession, and post-recession (Figure 4). A sixth and final iteration took place with the intention of recording water levels as they began to rise again in mid-summer, but because of an unusual drought in the summer of 2015, water levels remained too low to be able to capture any re-flooding (Figure 5).

Samples were also taken during a unique hydrologic "reversal," an event characterized by rapid re-flooding and subsequent dry-down. The hydrologic reversal occurred in a separate macrocosm (M1), and was included as a supplementary part of this study to compare the effects of varying rates of flooding and drying (Figure 6). Although this type of non-seasonal event is historically less common within the Everglades and only occurs under certain extreme conditions, there is an increasing need among scientific communities to understand the dynamics of rapid flooding, especially as climate change contributes to more intense precipitation events (IPCC, 2007; Diffenbaugh et al., 2005). For example, rapid flooding could have the effect of forcing biogenic gases out of wetland soils and into the atmosphere. The hydrologic reversal in M1 took place over a four-five week period (Figure 6), beginning on April 13, 2015, and samples were taken at shorter intervals to catch water levels before, during, and after short-term flooding. The sampling schedule in M1 was meant to mirror the experiment in M4, with six iterations occurring over a shorter time span.

Water levels were tracked using daily stage monitors at LILA, with information available on the "DBHYDRO” data site (my.sfwmd.gov/dbhydro/), managed by the 
South Florida Water Management District (SFWMD). To accurately reflect the water levels in both areas studied, stage monitors were chosen from within each macrocosm at the tail end of the inflow stations for M4 and M1 (http://goo.gl/208b1q). These stage monitors, "LILA4I-T” and "LILA1I-T,” were located just upstream of the study areas and provide data at fifteen-minute intervals as well as daily averages. A total of five landscape features were studied within LILA, referred to later in this study as "sites." These sites not only represented different ecological components within Everglades wetlands, but also varying levels of elevation: $\mathrm{HH}$, the highest elevation at $16.5 \mathrm{ft}$ NGVD (National Geodetic Vertical Datum), which typically remains dry throughout the year; $\mathrm{HL}$ at $15 \mathrm{ft}$ NGVD, which experiences partial flooding but is otherwise dry; MR, also situated at $15 \mathrm{ft}$ NGVD; SS at $14 \mathrm{ft}$ NGVD, which may experience a temporary dry-down but otherwise remains flooded throughout the year; and DS at $13.5 \mathrm{ft}$ NGVD, which remains inundated year-round.

Although there are several methods available to measure $\mathrm{CH}_{4}$ and $\mathrm{CO}_{2}$ levels from wetlands, most of these methods are complicated by varying water levels. Under non-flooded conditions, automated chamber methods have been employed to measure $\mathrm{CO}_{2}$ efflux from dry soil surfaces, using equipment such as the LI-8100A (LICOR, Nebraska, USA). Previous work at LILA has utilized this method to examine the relationship between hydrology and $\mathrm{CO}_{2}$ efflux (Schroeder, 2012), finding that rates of $\mathrm{CO}_{2}$ efflux generally decreased as flooding increased (Figure 7). In deeper areas where soils remain permanently flooded, various methods have attempted to quantify ebullition by collecting bubbling biogenic gases in "traps" (Comas et al., 2014). This gas trap 
method can be as simple as attaching vials to inverted funnels in submerged areas. However, this means that the traps can only be used in areas where water levels consistently remain high enough to keep the funnels and vials completely submerged (typically about $30 \mathrm{~cm}$ ). Because of the inherent sampling limitations of these methods, it was thought that pore-water sampling could more consistently provide samples for concentrations of $\mathrm{CH}_{4}$ and $\mathrm{CO}_{2}$ as water levels varied.

\section{Pore-water Sippers}

Soil pore-water was repeatedly sampled over the ten-month period, using porewater "sippers" which were installed at varying depths beneath the soil surface. Sippers were set to draw pore-water from depths of $5 \mathrm{~cm}, 10 \mathrm{~cm}, 25 \mathrm{~cm}, 40 \mathrm{~cm}$, and $60 \mathrm{~cm}$ beneath the soil/air or soil/water interface at each site (Figure 8), depending on the relative elevation of site. Because LILA was recently constructed (around 2001) as a recreated Everglades landscape, it did not contain - at the time of this study (2014-2015) the same accumulations of peat deposits that might be found in a naturally-formed region out in the Everglades. Therefore, landscape features that were constructed to occur at relatively higher elevations (namely tree islands and ridges) were situated over much thicker accumulations of peat soil, whereas areas at lower elevations (the deep and shallow sloughs) only possessed a small deposit of peat. For example, in some areas of the younger, northern macrocosms, there was only about $10-12 \mathrm{~cm}$ of peat soil available for sipper installation, and below these depths was a mix of sand and limestone leftover as the underlying foundation of LILA's construction. 
Additionally, because of the difference in the relative depths of peat at various sites within each macrocosm, some sipper sites included different combinations of sampling depths. The highest tree island site $(\mathrm{HH})$ featured a set of four depths: $10 \mathrm{~cm}$, $25 \mathrm{~cm}, 40 \mathrm{~cm}$, and $60 \mathrm{~cm}$ below the soil surface. The lower tree island site (HL) and the middle ridge (MR) each featured three depths: $10 \mathrm{~cm}, 25 \mathrm{~cm}$, and $40 \mathrm{~cm}$. The shallow slough (SS) sampled from depths of $5 \mathrm{~cm}$ and $25 \mathrm{~cm}$, while the deepest slough site (DS) only featured one depth at $5 \mathrm{~cm}$ below its submerged soil surface. In the slough sites, fewer sites were used for mainly two reasons. First, these areas generally lacked a substantial accumulation of peat soil, below which lay a barrier of sand and limestone. Sampling too close to this barrier would have made a comparison to the tree island soils difficult, since the focus was on gas production from highly organic peat soils. Second, the differences between sampling depths that were less than $5 \mathrm{~cm}$ apart in this case were deemed insignificant during preliminary testing, perhaps because the sippers used were not precise enough to differentiate between smaller-scale depths. Each depth at each site in M4 included a total of four replicate sipper tubes, while M1 only used three replicates for each depth at a site. Altogether, a total of 85 sipper tubes were used in both macrocosms: 52 tubes in M4, and 33 tubes in M1.

To compare relative depths across an entire macrocosm, the soil surface of the deep slough (DS) was set as a base elevation, with all other locations then occurring at elevations relative to this low point. The surface elevation of the $\mathrm{HH}$ site therefore measured at roughly $90 \mathrm{~cm}$ above the DS site, and its sipper depths (cited in the previous paragraph) were located at the following relative elevations: $80 \mathrm{~cm}, 65 \mathrm{~cm}, 50 \mathrm{~cm}$, and 30 
$\mathrm{cm}$, respectively. Setting the DS site as a baseline elevation allowed for a comparison of sipper depths across all sites in the macrocosm, as changing water levels were then imposed over each depth to give a degree of relative inundation for each individual sample. Adding a variable to measure inundation allowed for further analyses of the relationship between flooding and gaseous carbon production at each depth, across sites, and at the macrocosm-scale.

For the "sipper" method, a length of Tygon tubing (0.159 cm-I.D.) was run through a $0.95 \mathrm{~cm}-$ I.D. PVC pipe, with polypropylene Luer-Loc connectors on each side. At the bottom of the tubing, a male Luer fitting was secured inside the pipe by an o-ring and wrapped in Teflon tape. The Luer fitting was connected to a compressed foam tip (4.5 cm long, $0.6 \mathrm{~cm}$ diameter) from Porex Technologies, which filters pore water. This tip was secured inside the pipe, approximately $10 \mathrm{~cm}$ from the bottom, with a set of 16-20 horizontal slots cut across $4.5 \mathrm{~cm}$ (equal in length to the foam piece) along opposite ends of the pipe, allowing pore water to filter into the foam tip, but blocking larger particles from clogging the filter. To prevent outside air or water from entering the filter at any other point, the pipe was sealed below the foam piece with a $0.95 \mathrm{~cm}$ septum and a layer of marine-grade 5200 Polyurethane adhesive, and above the male Luer piece with tightlyfitting o-rings wrapped in Teflon tape. At the top of the pipe (above the surface), the female Luer fitting was attached to the other end of the Tygon tubing to create a vacuum, in order to purge and enable pore water samples to be drawn (DeLaune et al., 2013). After injecting 4-5 ml pore-water samples into a $20 \mathrm{ml}$ headspace vial purged with $\mathrm{N}_{2}$ gas, 
diffused $\mathrm{CO}_{2}$ and $\mathrm{CH}_{4}$ concentrations can be measured from the remaining headspace via gas chromatography (DeLaune et al., 2013).

\section{Redox Microelectrodes}

In situ reduction-oxidation (redox) measurements were also made during pore water sampling by inserting a system of "Flow-Thru” Redox and Reference Electrodes (Microelectrodes, Inc., New Hampshire, USA) via Tygon tubing and Luer fittings. The Flow-Thru system allowed for measurements of Redox potentials to be taken and attributed to each individual sample, as water was being drawn from sipper tubes into headspace vials. The microelectrodes were tested and calibrated prior to each sampling. Redox (Eh) potentials are measured in millivolts $(\mathrm{mV})$, and reflect the extent of reduction in flooded areas; those soils and depths that have been flooded and deprived of oxygen for longer periods exhibiting the lowest redox potentials. In non-flooded soils, oxygen is able to diffuse more freely through the soil matrix. Under these aerated conditions, soils may exhibit redox levels anywhere between +400 and $+700 \mathrm{mV}$ (Mitsch and Gosselink, 2007). During prolonged flooding, the diffusion of oxygen is reduced by about 10,000 times, and redox levels can range from +400 to $-400 \mathrm{mV}$ (Mitsch and Gosselink, 2007). After any remaining oxygen and all succeeding electron acceptors have been utilized, methanogenesis can begin, and typically occurs below a redox potential of -200 $\mathrm{mV}$.

\section{Soil Carbon Efflux}

Soil carbon efflux is a measurement of the rate of gas exchange from the soil surface into the atmosphere, across a certain area over time. For short-term, in situ 
measurements of soil $\mathrm{CO}_{2}$ efflux, a portable LICOR LI-8100A infrared gas analyzer (IRGA) with $20 \mathrm{~cm}$ 8100-103 chamber (LICOR, Nebraska, USA) was used over collars embedded in non-submerged soils within the M4W and M1W tree islands. The LI-8100A was physically moved between collars at each site to sample average rates of $\mathrm{CO}_{2}$ efflux for five minutes per sample, including a dead band of 30 seconds. While the IRGA was recording $\mathrm{CO}_{2}$ efflux rates, $\mathrm{CH}_{4}$ efflux was also measured by simultaneously drawing $5 \mathrm{ml}$ samples from interflowing air via gas-sampling port installed within the tubing of the LI-8100. These samples were then injected into $20 \mathrm{ml}$ headspace vials purged with $\mathrm{N}_{2}$ gas, and analyzed for concentrations of $\mathrm{CH}_{4}$. For flooded areas, the IRGA was fitted onto a collar installed in a floating foam platform, which allowed for sampling of carbon efflux from the surface of the water (Figure 9).

\section{Gas Traps}

Net $\mathrm{CO}_{2}$ and $\mathrm{CH}_{4}$ efflux via ebullition was measured using submerged gas "traps," made by securing inverted funnels $(17.8 \mathrm{~cm}$ diameter base, $22.9 \mathrm{~cm}$ height) to the submerged soil surface with cement rings (Figure 10). Single $20 \mathrm{ml}$ vials were then filled with water and secured upside-down to the top of inverted funnels with electrical tape, allowing bubbling gasses to displace water within the vials. Once secured to the traps, the vials were covered with aluminum foil to prevent sunlight from initiating photosynthesis within the clear glass vial (which could confound the data related to volumes and concentrations of gases contained inside the vials). To measure concentrations of $\mathrm{CO}_{2}$ and $\mathrm{CH}_{4}$ emitted via ebullition, and to avoid effects related to plant-mediated transport, 
gas traps were placed in soil plots with minimal vegetation (Sorrell \& Boon, 1994; Van der Nat et al., 1998; Grunfeld \& Brix, 1999).

\section{Gas Chromatography}

All water and gas samples were injected into $20 \mathrm{ml} \mathrm{N} 2$ gas-purged headspace vials, and diffused concentrations of $\mathrm{CO}_{2}$ and $\mathrm{CH}_{4}$ were then measured in the headspace using a Hewlett Packard 5890 Series II Gas Chromatograph (GC) fitted with an automated headspace sampler (HP-7694). Within the GC, $\mathrm{CO}_{2}$ is converted to $\mathrm{CH}_{4}$ by a methanizer (via Ni catalyst and $\mathrm{H}_{2}$ gas stream, Shimadzu MTN-1) at $450^{\circ} \mathrm{C}$ (Amador and Jones 1992, Amador and Jones, 1995), and then analyzed by flame ionization detection (FID) following retention on a HEYASEP-R column (Alltech, Inc.). Peak areas were measured by ELAB software version 4.02R, and converted into moles per volume based on a standard curve of known gas concentrations. As a consequence of the range and detection limits of the GC, some samples required one or more dilutions to incorporate higher sample concentrations along standard curves.

\section{Statistical Analyses}

All statistical analyses were conducted with SPSS (22.0, Chicago, Illinois, USA). The effect of varying elevation and changing water levels on concentrations of $\mathrm{CH}_{4}$ and $\mathrm{CO}_{2}$ were compared using one-way ANOVAs, with results considered statistically significant at the $p<0.05$ value. Post-hoc analyses included Tukey’s test of honest significant difference (HSD), and in some cases where this provided no significance, a less-conservative test of least significant difference (LSD) was also used. Non-normal 
data - such as outliers and extreme values - were sometimes removed before statistical analyses, except in cases where variability was of interest. Other variables not applicable to ANOVAs were compared and analyzed using basic bivariate correlations.

\section{RESULTS}

Over the course of this study, water levels at LILA reached seasonal highs of about $16.5 \mathrm{ft}$ NGVD, which was enough to temporarily inundate the highest elevations at the tree island head high site (HH). After the final sampling iteration in June 2015, water levels reached an abnormally-low point at about $14 \mathrm{ft} \mathrm{NGVD,} \mathrm{and} \mathrm{continued} \mathrm{to} \mathrm{drop}$ during the summer drought, exposing much of the slough area that typically remains flooded year-round (Figure 5). In M4, pore-water concentrations of $\mathrm{CH}_{4}$ ranged from $13.09 \mu \mathrm{mol} \mathrm{L} \mathrm{L}^{-1}$ in the highest tree island site $(\mathrm{HH})$ to $22.71 \mathrm{mmol} \mathrm{L}^{-1}$ in the lowest slough site (DS), and concentrations of $\mathrm{CO}_{2}$ ranged from $595 \mu \mathrm{mol} \mathrm{L}^{-1}$ in the $\mathrm{HL}$ site to 49.04 mmol L ${ }^{-1}$ in the tree island $\mathrm{HH}$ site (Table 2). Similar results were found in M1, where $\mathrm{CH}_{4}$ concentrations ranged from $11.26 \mu \mathrm{mol} \mathrm{L}^{-1}$ in the highest site $(\mathrm{HH})$ to $3.5 \mathrm{mmol} \mathrm{L}^{-1}$ in the SS site, and concentrations of $\mathrm{CO}_{2}$ ranged from $619 \mu \mathrm{mol} \mathrm{L}^{-1}$ in the MR site to $30.84 \mathrm{mmol} \mathrm{L}^{-1}$ in the tree island $\mathrm{HH}$ site (Table 3). Overall, M4 proved to be the more productive site for biogenic gases, reflecting a longer hydroperiod compared to M1.

In general, the differences in $\mathrm{CH}_{4}$ and $\mathrm{CO}_{2}$ production were most noticeable between sites at opposite ends of the elevation spectrum. The variability between all sites in both macrocosms was exceedingly high, and almost always close to or higher than the 
means themselves. Nevertheless, some overall trends and differences between certain sites could still be derived. Between the highest point of the tree island $(\mathrm{HH})$ and the sloughs (SS and DS), there were significant differences in both concentrations of $\mathrm{CH}_{4}$ and $\mathrm{CO}_{2}$. Referring to a boxplot of $\mathrm{CH}_{4}$ concentrations across all Sites in M4 (Figure 11), the mean value for mmol L-1 $\mathrm{CH}_{4}$ increased steadily as elevation decreased: from 2.19 (HH), 2.461 (HL), 3.178 (MR), 3.65 (SS) to 4.455 (DS). Similarly for $\mathrm{CH}_{4}$ concentrations in M1 (Figure 12), the highest means occurred in the SS and DS sites, respectively. At the opposite end of the elevation spectrum, mean $\mathrm{CH}_{4}$ production was higher in the $\mathrm{HH}$ site than both the HL and MR sites, though still lower than the highest production site (SS) by an order of magnitude. With this one exception in the HH site, it was otherwise clear that lower elevations, which corresponded to higher water levels over longer periods, resulted in greater production of $\mathrm{CH}_{4}$ overall.

Concentrations of $\mathrm{CO}_{2}$ were also highest at higher elevations $(\mathrm{HH})$, and decreased from the HL to MR sites, at which point they rose again in either the SS or DS site. Variability was also high in these results, but concentrations of $\mathrm{CO}_{2}$ produced were generally greater than $\mathrm{CH}_{4}$ concentrations by one-three orders of magnitude (Figure 13). In a boxplot for $\mathrm{CO}_{2}$ concentrations in $\mathrm{mmol} \mathrm{L}^{-1}$ across sites in M1 (Figure 14), the standard deviations were the lowest of any test (though still above 50\% mean values), and the means decreased from $10.36(\mathrm{HH}), 7.08(\mathrm{HL}), 6.075$ (MR) to $4.504(\mathrm{SS})$, then rose again to 6.315 (DS). While $\mathrm{M} 1$ showed a higher potential for $\mathrm{CO}_{2}$ production over short-term periods - resulting from the rapid flooding and drying which is characteristic of the hydrologic reversal - M4 showed greater average potential for the same number of 
sampling iterations over a longer span. In fact, in all tests, M4 was observed as a more productive system overall, as average concentrations taken from the seasonally-flooded macrocosm (M4) generally exceeded those in the rapidly-flooded M1 (Tables 2 and 3).

There were a few main advantages and purposes for installing pore-water sipper tubes throughout each site of the LILA macrocosms in this experiment. First, it was deemed an efficient way to measure the effect of water levels on soil conditions and respective biogenic gas production. The sippers themselves were relatively inexpensive and easy to construct, so this represented a cost-effective way to make repeated measurements over dozens of individual sampling locations. Second, this method would allow for differentiation in the analysis between the effects of inundation at various depths within the soil matrix. Finally, it was hoped that sampling pore-water might be slightly less susceptible to the changing availability of water, since tree islands (such as those in LILA) have been found to hydraulically pull groundwater toward their roots, thereby sustaining water levels at higher elevations within tree islands than the surrounding water table (Sullivan et al., 2010; Sullivan et al., 2012). Permanentlyinstalled pore-water sippers therefore allowed for more consistent sampling across sites over seasonal changes in water levels.

As the hydrology at LILA was controlled according to the operational hydrograph, water levels varied from seasonal highs to lows across the macrocosms. In M4 - the primary focus for this study - pore-water was often unavailable for sample collection, especially in shallower sipper depths among the sites at higher elevations. Of the total 13 
sipper tubes deployed in four replicates, at up to four depths across five sites, over the six main sampling events in M4, pore-water was not able to be collected from 41 of 312 samples (about 13.14\% of the total expected). This created gaps within the dataset that prevented regressions from being tested on certain variables. The nature of missing data was here considered to be "missing not at random" (MNAR), since other factors - in this case, semi-controlled water levels - caused higher elevations and shallow depths to be unable to provide samples at certain points along the hydrograph.

To account for subsequent gaps in the dataset, a separate set of bivariate correlations tests were run to assess the relationship between all appropriate variables. Some variables were also added post-sampling to get a better sense of the overall effect of water levels on production of $\mathrm{CH}_{4}$ and $\mathrm{CO}_{2}$. For example, Inundation was included as a variable, measured simply as the difference between Stage (water levels) and sampling depths of sipper tubes for any given sample. Another variable was included to compare Days Flooded, as the number of days that stage levels had been consecutively higher than any given sampling depths. These variables were made possible using stage information provided by SFWMD's DBHYDRO database, as well as standardized NGVD elevations for all macrocosm features, which were established during LILA's construction.

Concentrations of $\mathrm{CH}_{4}$ and $\mathrm{CO}_{2}$ were correlated with hydrology across both macrocosms during periods of flooding and drying, using data taken from pore-water sippers. The first set of correlations tests applied only to M4, where sampling occurred from September 2014 until June 2015. Three different flooding variables - Stage (water 
levels), Inundation, and Days Flooded - each correlated positively with $\mathrm{CH}_{4}$ production in M4 (Table 4). That is, as water levels increased and were sustained for longer periods over several months, there was a general correlation with higher concentrations of $\mathrm{CH}_{4}$. And although the hypotheses supposed that $\mathrm{CO}_{2}$ concentrations might decrease with increasing water levels, a separate correlation supported that as $\mathrm{CH}_{4}$ concentrations increased, so did $\mathrm{CO}_{2}$ concentrations. Therefore, whenever conditions promoted decomposition and carbon was being broken down, this resulted in general increases for both $\mathrm{CH}_{4}$ and $\mathrm{CO}_{2}$ production. The rates of production for each gas may have differed, but this correlation indicated that each site location and depth was capable of producing $\mathrm{CH}_{4}$ and $\mathrm{CO}_{2}$ under both wet and dry periods.

Taken from microelectrode readings during pore-water sampling, Redox values were found to correlate negatively with both Stage and Inundation, illustrating that higher water levels corresponded with lower redox potentials, and more reduced soil conditions. Although decreases in Redox levels were expected to coincide with increased $\mathrm{CH}_{4}$ production - as flooded and reduced conditions prime soils for methanogenesis - no related correlations were found to be statistically significant. However, increased $\mathrm{CH}_{4}$ production was still observed in relation to rising water levels. Ratios of $\mathrm{CO}_{2} / \mathrm{CH}_{4}$ in $\mathrm{M} 4$ also correlated negatively to the three main variables for water; Stage levels, Inundation, and Days Flooded. These results might alternatively support the expectation that with higher water levels maintained over longer periods, more $\mathrm{CH}_{4}$ is produced relative to $\mathrm{CO}_{2}$, which decreases over the same spans. 
Since M1 reflected a shorter timeframe and hydroperiod compared to M4, it was expected to yield slightly different results, in terms of how flooding rates would affect production of $\mathrm{CH}_{4}$ and $\mathrm{CO}_{2}$. To initiate methanogenesis, soils typically need to remain flooded for extended periods before alternative electron acceptors are exhausted. As Inundation and Days Flooded increased, soils became more reduced and Redox levels likewise decreased (Table 5). And as Redox levels decreased, concentrations of $\mathrm{CH}_{4}$ expectedly increased. These results support the hypothesis that higher water levels and prolonged flooding will push anaerobic conditions to lower Redox potentials, thereby increasing $\mathrm{CH}_{4}$ production. Increased concentrations of $\mathrm{CH}_{4}$ in $\mathrm{M} 1$ also correlated positively with Days Flooded (an expected result that was not found in $\mathrm{M} 4$ ), and $\mathrm{CO}_{2}$ concentrations decreased as Days Flooded increased. Finally, the $\mathrm{CO}_{2} / \mathrm{CH}_{4}$ ratios in M1 decreased as Redox levels decreased and Days Flooded increased. All of these results illustrate important relationships that were expected to appear stronger in M4 during seasonal flooding. Nevertheless, the correlation data generally supported the main hypotheses: that flooded conditions led to increased $\mathrm{CH}_{4}$ production, while dry conditions led to increased $\mathrm{CO}_{2}$ production.

All $\mathrm{CH}_{4}$ samples drawn from the LICOR were analyzed via gas chromatography, and almost all concentrations of $\mathrm{CH}_{4}$ taken by this method were below detectable limits. However, efflux measurements from the IRGA did not necessarily account for ebullition events, which have shown high concentrations of $\mathrm{CH}_{4}$. The samples taken from the slough sites produced more $\mathrm{CH}_{4}$ than the corresponding tree island and ridge sites from the same sampling periods, and this difference was often observed by at least one order of 
magnitude. At all LICOR sites, regardless of hydrologic conditions and whether the IRGA was run above dry soil or water surfaces, there was not enough $\mathrm{CH}_{4}$ to be considered detectable on the GC, and larger sampling volumes would therefore be recommended in future studies.

As previously mentioned, whenever water levels fell below certain sampling elevations, the corresponding pore-water sippers were often unable to draw any samples to be run for GC analysis. Subsequent data gaps occurred primarily for the highest sampling elevations on the tree island HH and HL sites. Although the ridge (MR) site was located at the same elevation as the tree island HL site, it did not exhibit the same difficulty in sampling water until the drought brought water levels below seasonal lows. Conversely, the slough (SS and DS) sites were always able to provide samples for all corresponding sipper elevations. Because missing data was considered "missing not at random” (MNAR) when water levels were not high enough to make pore-water samples available at certain sipper tube depths, data analyses were only possible and (statistically) sound via certain regressions. In the end, this meant that gas concentrations needed to be compared across sites overall, rather than sampling depths. "Sites" then became treatments of relative depths and related conditions themselves.

A one-way analysis of variance (ANOVA) was conducted to evaluate the relationship between Sites - which represent varying elevations, and therefore varying periods of inundation - and the concentrations of emitted $\mathrm{CH}_{4}$ and $\mathrm{CO}_{2}$. Because different hydrologic conditions were maintained in each of the two macrocosms (with M4 
reflecting a gradual, seasonal flooding and drying from September to June, while a “reversal” implemented a rapid re-flooding within M1 from April to May), separate tests were conducted for each macrocosm and respective Sites. The independent variable Site location - included the five main sites: HH, HL, MR, SS, and DS. The dependent variables were the concentrations for either $\mathrm{CH}_{4}$ or $\mathrm{CO}_{2}$, measured in $\mu \mathrm{mol} \mathrm{L}{ }^{-1}$. With the many variables involved in this study, and the data gaps that arose from low water availability in certain areas, one-way ANOVAs represented the best method for testing for significant differences in gas concentrations across changing elevations.

The variability in data across all sites was high; a result that reflects the decision to group sampling locations by sites, thereby incorporating multiple sipper depths over the span of seasonally-changing water levels. For concentrations of $\mathrm{CH}_{4}$ within $\mathrm{M} 4$, there were no significant differences between sites overall, $\mathrm{F}(4,266)=1.61, p=0.17$, as the variability was too high to distinguish individual sites using Tukey’s test of honest significant difference (HSD). However, a post-hoc analysis using a test of least significant difference (LSD) showed a difference between the highest tree island site, $\mathrm{HH}$, and the lowest slough site, DS, $p=.038$, where the DS site produced a mean difference of $2265 \mu \mathrm{mol} \mathrm{L}^{-1}$ more $\mathrm{CH}_{4}$ than the $\mathrm{HH}$ site. The mean values of all M4 sites suggested that as elevation decreased and water levels likewise increased, there was a general increase in $\mathrm{CH}_{4}$ produced (Figure 11). This relationship was confirmed in other results, as $\mathrm{CH}_{4}$ concentrations were found to correlate negatively to site elevations. However, the variability among M4 sites was too high to provide significance: in fact, the variability 
actually increased as the means increased from higher to lower elevations, and in all cases the standard deviation was greater than the mean values for each site.

Concentrations of $\mathrm{CO}_{2}$ also yielded highly variable results, but generally showed a starker contrast between sites in M4. The two highest elevations at the tree island sites had the highest concentrations of $\mathrm{CO}_{2}$ overall, $\mathrm{F}(4,266)=3.33, p=.011$. The differences were strong enough here to be considered significant using a more conservative post-hoc test - Tukey's HSD test - which showed that both sites on the tree island produced significantly more $\mathrm{CO}_{2}$ than the ridge (Figure 13). Compared to the $\mathrm{MR}$ site, $\mathrm{HH}$ averaged 6.85 mmol L ${ }^{-1}$ more $\mathrm{CO}_{2}, p=0.023$, while $\mathrm{HL}$ produced only slightly less, $6.68 \mathrm{mmol} \mathrm{L}^{-1}$ more $\mathrm{CO}_{2}$ on average, $p=.043$. The two tree island sites were not significantly different from each other. The slough sites (SS and DS) each produced more $\mathrm{CO}_{2}$ than the ridge (MR) site, but the differences were not statistically significant. In general, the greatest $\mathrm{CO}_{2}$ concentrations occurred at higher elevations; a result of less flooding and greater oxidation, as exemplified by the experiment in M1 (Figure 14).

The ratios of $\mathrm{CO}_{2} / \mathrm{CH}_{4}$ were also analyzed by sites along an elevation gradient in each macrocosm. Since each GHG tested had a relatively different GWP, this analysis was included to potentially inform future restoration efforts on the relative differences of GHG potential for these sites. This variable was calculated simply as the quotient of the concentrations (mol:mol) of $\mathrm{CO}_{2}$ (dividend) over $\mathrm{CH}_{4}$ (divisor) for each respective sample. However, because of the relative differences in production of each of these gases 
during certain hydrologic events, some complications arose in assessing the $\mathrm{CO}_{2} / \mathrm{CH}_{4}$ ratios, which required some adjustments to be able to include this variable.

During dry-down events in certain areas, where water levels receded and previously-flooded soils became exposed and oxidized, $\mathrm{CH}_{4}$ production was much lower than that of $\mathrm{CO}_{2}$. Each run of samples analyzed on the GC contained a set of Standards to determine the range of detection, including standard volumes of $\mathrm{CH}_{4}$ in 10, 50, 100, 250 and $400 \mu \mathrm{L}$, as well as purged blanks containing no injected $\mathrm{CH}_{4}$. Under drier conditions, $\mathrm{CH}_{4}$ concentrations among higher elevations were often measured at less than the GC's detectable limit provide by the blank standards. In these cases, the values for $\mathrm{CH}_{4}$ could be treated as zero (non-detectable) and eliminated from the dataset prior to statistical testing. However, in order to be able to continue testing the ratios of $\mathrm{CO}_{2} / \mathrm{CH}_{4}$, a value was imposed that represented a measure of $\mathrm{CH}_{4}$ falling between the minimum blank standard and the lowest standard of $10 \mu \mathrm{L} \mathrm{CH}_{4}$. This resulted in a much larger value for the $\mathrm{CO}_{2} / \mathrm{CH}_{4}$ ratio of these samples, allowing these locations to reflect the fact that these sites and sampling elevations were primarily producing $\mathrm{CO}_{2}$, after becoming oxidized and reinitiating decomposition.

Given that $\mathrm{CH}_{4}$ increased and $\mathrm{CO}_{2}$ decreased with decreasing elevation, ratios of $\mathrm{CO}_{2} / \mathrm{CH}_{4}$ were likewise predicted to decrease from higher to lower areas, as flooding increased. This relationship was found as expected, F $(4,266)=5.41, p<.001$ as the ratios decreased along a decreasing elevation gradient (Figure 15). The highest tree island site $(\mathrm{HH})$ had significantly higher $\mathrm{CO}_{2} / \mathrm{CH}_{4}$ ratios than the ridge and slough sites. On 
average, the ratios of the $\mathrm{HH}$ site were 29.75 units greater than the MR site, $p=.007$;

38.01 units greater than the SS site, $p=.001$; and 38.95 greater than the DS site, $p=.014$. A less conservative LSD test showed that between tree island sites, the average $\mathrm{CO}_{2} / \mathrm{CH}_{4}$ ratio at $\mathrm{HH}$ was 19.28 units greater than $\mathrm{HL}, p=.036$. The variability also shrank as elevation decreased from the tree island (HH and HL) sites - where variability was very high - to the ridge and slough sites (Figure 15).

Slightly different patterns were observed in results from pore-water data collected in M1; an expected result which most likely reflects the temporal differences between seasonal flooding compared to a rapid re-flooding in the hydrologic reversal. However, aside from the different flooding timeframes between M4 and M1, there were other hydrologic differences between the two macrocosms and their respective experiments. For example, the experiment in M1 occurred at a later point in the seasonal hydrograph, when conditions were already drier and more areas across the LILA macrocosms were exposed and oxidized for decomposition (Figure 5). Also, peak water levels in M1 during the re-flooding were only able to be raised to under $15.5 \mathrm{ft}$ NGVD, whereas peak levels in M4 reached $16.5 \mathrm{ft}$ NGVD (Figure 5). The differences in timing and duration of sampling between M4 and M1 were expected to contribute some variability to the results in both macrocosms, but otherwise, the general relationships between elevation and biogenic gas production remained relatively consistent.

In M1, the SS site (rather than the DS site) produced the highest overall $\mathrm{CH}_{4}$ concentrations and had the greatest variability, F $(4,124)=12.78, p<.001$ (Figure 12). 
Here, there were significant differences between the SS site and all other sites: where SS averaged $951 \mu \mathrm{mol} \mathrm{L}{ }^{-1}$ more $\mathrm{CH}_{4}$ than the $\mathrm{HH}$ site, $p<.001 ; 1382 \mu \mathrm{mol} \mathrm{L}^{-1}$ more than the HL site, $p<.001 ; 1256 \mu \mathrm{mol} \mathrm{L}^{-1}$ more than the MR site, $p<.001$; and $902 \mu \mathrm{mol} \mathrm{L}{ }^{-1}$ more $\mathrm{CH}_{4}$ than the DS site, $p=0.001$. Additionally, a less-conservative LSD test showed some differences between the tree island sites, $p=.018$, where the HH site produced a mean difference of $431 \mu \mathrm{mol} \mathrm{L}^{-1}$ more $\mathrm{CH}_{4}$ than the HL site. The unique pattern observed among the means across each site might be a result of the different hydroperiods in M1 and M4. Although the highest site (HH) was specifically expected to emit the least $\mathrm{CH}_{4}$, and the lowest site (DS) to likewise emit the most, the greatest $\mathrm{CH}_{4}$ production was nonetheless found at lower sites where flooding persisted for the longest periods.

The dynamics of $\mathrm{CO}_{2}$ concentrations in $\mathrm{M} 1$ were found to be similar to those in $\mathrm{M} 4$, as the highest elevation tree island $\mathrm{HH}$ site produced significantly more $\mathrm{CO}_{2}$ than the ridge and slough sites, $\mathrm{F}(4,124)=5.155, p=0.001$ (Figure 14). The highest tree island site $(\mathrm{HH})$ averaged $4.28 \mathrm{mmol} \mathrm{L}^{-1}$ more $\mathrm{CO}_{2}$ than $\mathrm{MR}, p=0.006 ; 5.85 \mathrm{mmol} \mathrm{L}^{-1}$ more than SS, $p=0.001$; and $4.04 \mathrm{mmol} \mathrm{L}^{-1}$ more than DS, $p=0.048$. There was also a difference between the two tree island sites via a less-conservative LSD test, where the $\mathrm{HH}$ site produced a mean difference of $3.28 \mathrm{mmol} \mathrm{L}^{-1}$ more $\mathrm{CO}_{2}$ than $\mathrm{HL}, p=0.011$. Again, as higher elevations remained dry for longer periods, the relatively-greater availability of oxygen caused these areas to produce the highest concentrations of $\mathrm{CO}_{2}$. 
Finally, while the test results for $\mathrm{CH}_{4}$ concentrations in $\mathrm{M} 1$ provided a unique pattern in mean production across sites, the pattern for mean $\mathrm{CO}_{2} / \mathrm{CH}_{4}$ ratios in $\mathrm{M} 1$ appeared to demonstrate an inverse relationship (Figure 16). Ratios of $\mathrm{CO}_{2} / \mathrm{CH}_{4}$ in $\mathrm{M} 1$ were significantly higher in both tree island sites compared to the slough sites, F $(4,124)$ $=6.815, p<.001$, and the highest $\mathrm{HH}$ site had a $\mathrm{CO}_{2} / \mathrm{CH}_{4}$ ratio which was, on average, 137.55 units greater than SS, $p=.005$, and 123.78 units greater than the DS site, $p=.016$. Unexpectedly, the mean $\mathrm{CO}_{2} / \mathrm{CH}_{4}$ ratio across $\mathrm{M} 1$ sites was highest at the HL site, which was significantly greater than both the slough sites: SS, $p=.001$, by a mean difference of 161.82 ; and DS, $p=.003$, by 148.05 . This result may be related to an interaction with tree root respiration, or differences in oxidization between the rhizospheres of the tree island HH and HL sites. The overall patterns observed in concentrations between M4 and M1 were most likely related to the obvious differences in timing and extent of flooding. Still, the underlying relationships between elevation and biogenic gas production remained relatively consistent in both macrocosm experiments.

\section{DISCUSSION}

Statistical testing was largely unable to analyze the differences in $\mathrm{CH}_{4}$ or $\mathrm{CO}_{2}$ production at the various depths of sippers within each macrocosm, although the data still point to some general patterns and relationships. Previous studies have shown that average $\mathrm{CH}_{4}$ concentrations tend to increase at lower soil depths. In a study of boreal peatlands, Moore \& Knowles (1990) found that soil profiles at $100 \mathrm{~cm}$ below the surface averaged more than double (and up to four times) the $\mathrm{CH}_{4}$ concentrations than those at 
10 cm depths. In southern Everglades marl soils, Happell et al. (2003) saw increases in $\mathrm{CH}_{4}$ concentrations between $300-1000 \%$ at depths below $5 \mathrm{~cm}$ from the soil surface. Although none of the individual sipper depths at LILA exceeded $60 \mathrm{~cm}$, greater $\mathrm{CH}_{4}$ production occurred at the lowest depths, and average $\mathrm{CH}_{4}$ concentrations were up to three orders of magnitude greater at the lowest slough elevations compared to the highest tree island elevations (Table 4). Overall, $\mathrm{CH}_{4}$ production was greatest at the lowest elevations, and $\mathrm{CO}_{2}$ production conversely was greatest at the highest elevations.

Previous studies have also shown clear accelerations in methanogenesis after prolonged flooding (Kannenberg et al., 2015), although measurements of redox potentials taken during pore-water sampling in this experiment did not show severely-reduced conditions. Redox levels rarely approached $-200 \mathrm{mV}$, which typically marks the point at which soils are reduced enough to initiate methanogenesis. Despite this unexpected result, however, concentrations of $\mathrm{CH}_{4}$ were relatively high compared to results from previous studies which used similar sampling methods (Happell et al., 2003). One possible explanation for this is that the soils were simply not flooded for long enough to exhaust the availability of alternative electron acceptors. It is also possible that the sipper tubes, although designed and tested to be air-tight, may have created a pathway from the aboveground surface to the soil matrix underneath. The sippers were designed to be minimally-invasive and prevent soils from being disturbed during sampling, but it’s possible that the process of collecting samples could have inadvertently aerated the soils surrounding the tubes. In either case, if oxygen were accidentally made available at the 
sampling depths - even in small amounts - it could have stalled the advancement of methanogenic conditions, thereby reflecting higher redox potentials.

It could also be the case that the soil conditions at LILA during this experiment simply did not become as reduced as might have been expected. Thomas et al. (2009) showed that redox potentials at shallow depths of flooded Everglades soils can reach levels of about $-200 \mathrm{mV}$, which is close to levels recorded within this experiment at LILA. The results from this study confirm that soils can at least approach the redox range necessary for methanogenesis. However, moderately or highly impacted soils have also been found to stabilize at higher, less-reduced levels (Thomas et al., 2009), which may have applied to the soils at LILA during this experiment.

Efflux rates of $\mathrm{CO}_{2}$ derived from the LICOR LI-8100A were typically much higher under drier conditions: both before soils became flooded, and after previouslyflooded soils were exposed and oxidized (Figures 17 and 18). There was some variability between sites, but efflux rates were also generally highest at higher-elevation sites, such as in the tree island and ridge sites. The only exception occurred in the final sampling iteration, at the beginning of what proved to be an unusually-long drought during summer 2015, after water levels had continued to drop beyond controllable levels and fell below seasonal averages (Figures 3 and 5). At this time, much of the ridge and shallow slough surface became exposed, including areas that would otherwise have remained flooded year-round, as per the operational hydrograph. The only areas that remained flooded were the lowest sections of the DS and SS sites, and these (particularly the DS site) exhibited 
the highest LICOR efflux rates in the last iteration, during the dry-down following prolonged flooding from the wet season (Figures 17 and 18).

The sipper and LICOR methods were employed to account for biogenic gases within the soil matrix and those that would efflux from soil/water surfaces, respectively. The gas traps were included as a commonly-used method of capturing gases that escape from flooded soils through the water column via ebullition. Samples from gas trap vials were measured for both the volume collected as well as for the relative concentrations of $\mathrm{CH}_{4}$ and $\mathrm{CO}_{2}$. Previous studies with gas traps have typically assumed that ebullition samples are predominantly made up of $\mathrm{CH}_{4}$, which has led researchers to focus primarily on quantifying the volume of $\mathrm{CH}_{4}$ leaving flooded systems. It therefore seemed worthwhile to attempt to quantify and qualify the gases being released via ebullition. However, as a result of some inherent limitations of this method (including gas trap volume and water depth), there were difficulties in capturing a precise profile of ebullition, as an important aspect of $\mathrm{CH}_{4}$ production in wetlands.

Because of the unpredictable nature of ebullition, $\mathrm{CH}_{4}$ production by this method has been somewhat difficult to quantify, and represents an ongoing knowledge gap. Previous studies have measured gas releases from boreal peatlands using gas chambers, while less research has been done in tropical or subtropical areas, until more recently. Comas and Wright (2014) have used ground-penetrating radar (GPR) and slightly more sophisticated gas traps to measure biogenic gas releases from two sites in northern Everglades peatlands, one of which was located within LILA in M3. Their results show 
that the production and efflux of $\mathrm{CH}_{4}$ from these areas is very highly variable, both spatially and temporally (Comas and Wright, 2014). The nature of these ebullition events is such that they accumulate under flooded soils, until they have enough mass to be able to bubble up through the soil. This bubbling tends to occur in very unpredictable ways, as varying volumes of gases may be released at random intervals across a wetland landscape. A general lack of uniformity and predictability here can complicate the task of attempting to characterize ebullition beyond a small scale.

The inherent depth-limitation of the gas traps posed a logistical challenge during sampling, as water levels could not always be predicted or controlled. For the gas traps to function as intended, the surface of the water needed to remain above the top of the vial that was affixed to each trap. Therefore, water levels needed to be high enough at all times to cover the traps entirely, so that the water would remain inside the upside-down vial, allowing gas to displace it and collect in the overturned vial. As water levels decreased in the early months of the year after peak levels (from January until May), fewer locations had enough water to support the use of gas traps. If water levels fell below the point where the vial was secured to the trap, it became impossible to know if the concentrations contained within the vial were reliable and accurate, as air would often escape or find its way into the trap through the tape. Sometimes the pressure of the contained gases would actually open holes along the contours of the tape and compromise the integrity of the trap. Ultimately, only the deeper areas of the sloughs were able to maintain consistently-high water levels necessary to incorporate gas traps. 
The variable nature of ebullition also created a sizeable obstacle to this method. First, the timing and the amount of ebullition events are highly variable and unpredictable (Comas et al., 2014). The gas traps used in this experiment at LILA were relatively small compared to those used in prior studies, but they were intended to be minimally invasive to the surrounding soils. Installing the traps only required that they be secured to the submerged soil surface by positioning a cement ring over the top of the trap. However, this meant that sample collection needed to be very delicate; during collection and replacement of the vials, any disturbance to the trap or surrounding soil could trigger ebullition. Even while using a small kayak to avoid stepping in nearby areas, it was difficult to manipulate the vials without disturbing the soil and triggering an ebullition event in or around the gas trap. Since ebullition is naturally variable, the flaws in the gas trap design made it impossible to collect data that accurately and reliably reflected the emissions of biogenic gases from these study sites.

The $20 \mathrm{ml}$ vials used this study were also limited by their volume. To precisely measure the volumes of gases released into the traps, a certain amount of water needed to remain, un-displaced by gas. Because the timing and volume of ebullition was highly unpredictable, it was difficult to capture an accurate profile for rates of ebullition. After about 5-7 days, some vials would already be overfilled with gas, while others barely had enough to be able to sample. Those same vials with smaller volumes of gas, if left out in the field for another 5-7 days, would then often be overfilled with gas. There was no discernible, predictable window in which to collect samples that would provide volumetric measurements. If the vials overfilled with gas and no water remained un- 
displaced, it was impossible to determine the volume that had been produced in that location. Using larger vials could provide a larger window in which to collect appropriate volumes for samples, rather than trying to time it so that gas volumes were emitted between a 2-20 ml range. Comas and Wright (2014) have also recently shown a high degree of variability in results from studies on ebullition in nearby Everglades areas.

Another unexpected issue with the gas trap method was made clear by some unidentified wildlife (probably alligators, but also possibly deer), whose recurring trails through gas trap plots demonstrated a security flaw. As stated above, the traps were relatively small, and easily anchored to the submerged soil surface with a cement ring (only slightly larger in diameter than the traps themselves). The setup worked to keep the traps held down, but also made them slightly top-heavy. If the cement rings had been permanently affixed to the traps, they may have been sturdier and less likely to be disturbed. However, considering the size of the wildlife that routinely left trails in the sloughs, even larger traps might not have avoided disturbances.

In the end, very few samples collected via gas traps were able to be measured for volume produced, but most samples were able to be analyzed on the $\mathrm{GC}$ for $\mathrm{CH}_{4}$ and $\mathrm{CO}_{2}$ concentrations. Although the results were highly variable (Figure 19), $\mathrm{CH}_{4}$ concentrations from gas traps were much higher than samples collected by sipper and efflux methods, often by one-three orders of magnitude (Figure 20). Concentrations of $\mathrm{CO}_{2}$ were also highest from gas trap vials, suggesting that these bubbles contain more than simply $\mathrm{CH}_{4}$, as past studies have assumed. Unfortunately, this experiment did not 
provide evidence to indicate the exact timing or spatial variability of emissions from wetland soils. The results of this study suggest that gas traps make for a relatively inexpensive method of sampling, but were ultimately unable to capture an accurate profile for patterns of ebullition under these conditions. Further studies should therefore attempt to both quantify and qualify the temporal and spatial variability of gas produced via ebullition. This should include a wider study of peatlands in varying climates, and particularly for those tropical and subtropical regions, which are relatively under-studied but have been estimated to account for up to $19 \%$ of the total global carbon pool (Page et al., 2011).

In both macrocosms, representing differing hydrologic scenarios of long and short hydroperiods, certain tests responded as expected (albeit via different variables), while others did not. Separately, each set of results may point to some general trends that may be a reflection of the differing hydrographs. Previous studies which point to seasonal water levels as the driving factor behind biogenic gas production have found that $\mathrm{CH}_{4}$ emissions are typically highest among continually-flooded peatlands and open-water ponds, as well as adjacent wetland zones, where the water table rose close to or above soil surfaces (Malone et al., 2013; Bubier and Moore, 1993). Some individual correlations alone may not have lent much support to the hypotheses, but there were similar trends to be noticed overall. Together, the results from M4 and M1 suggest that soils at greater depths, in sites with lower overall elevation, and where water levels remained higher for longer, became more reduced and resulted in greater production of $\mathrm{CH}_{4}$, with the opposite being true for $\mathrm{CO}_{2}$ production. 
Because elevation differences were compared on a micro-topographic scale, the variability in results among sites was high, and the differences between adjacent sites were often too subtle and indistinct to be statistically significant. Perhaps if sampling had focused on the two extremes of this elevation spectrum - the tree island $\mathrm{HH}$ compared to the slough (SS or DS) sites - more data could have been collected to distinguish between contrasting elevations. Since the landscape profile of the Everglades is characteristically comprised of subtle changes in topography, however, it seemed important to attempt to parse any differences among sites along this elevation gradient. And between the two endpoints on this spectrum - the tree island and slough sites - some significant differences were observed in this study, in both $\mathrm{CH}_{4}$ and $\mathrm{CO}_{2}$ production. As elevation decreased, $\mathrm{CH}_{4}$ production consistently increased, and while relatively high concentrations of $\mathrm{CO}_{2}$ were also found in the deepest slough sites, the highest $\mathrm{CO}_{2}$ production came from the highest tree island sites: HH and HL, respectively.

While the lower tree island (HL) site offered less distinction for high or low levels of $\mathrm{CH}_{4}$ or $\mathrm{CO}_{2}$, the variability observed at this site may be more strongly tied to the nature of its location. Within the LILA tree islands, the HL site reflects a subtle transition zone with a very gently-sloping bank to the water's edge. This type of area likewise experiences much higher variability in water levels throughout the year, from complete flooding to total dry-down, and this dynamic hydrology can have a major impact on the processes involved in biogenic gas production (Blodau and Moore, 2003; Jimenez et al., 2012). This was especially true in M1, where the hydrologic reversal drove a rapid 
change in water levels over a shorter timeframe, and where overall $\mathrm{CH}_{4}$ emissions were considerably less than in M4 (Figures 11 and 14).

Despite the fact that the MR site is situated at the same elevation as the tree island HL site, the results from site-to-site testing suggested that the MR site acted more like a lower-elevation site, compared to the HL site. Studies have shown that vegetation plays a major role in affecting efflux rates, and the differences between the HL and MR sites could be caused by their obvious differences in vegetation makeup (Amador and Jones, 1995; Torn and Chapin, 1993). Among the sites chosen within LILA, the MR site was entirely surrounded by only a few types of graminoids, while the HL site contains a much wider diversity of vegetation - including trees - and these distinct vegetation types can affect hydrologic and biogenic processes (Bachoon and Jones, 1992; Stofella et al., 2010; Sullivan et al., 2010; Sullivan et al., 2012).

Other factors affecting biogenic gas production could be linked to the unique role that tree islands play among the ridge-and-slough landscape. In Everglades areas, tree islands are considered biogeochemical hotspots for their tendency to contain higher concentrations of nutrients (particularly phosphorus) compared to the surrounding ridges and sloughs (Rodriguez et al., 2014; Wetzel et al., 2005; Ross et al., 2006). Likewise, certain "transition zones" in wetlands - such as the banks of tree islands, especially those with shallow slopes that are exposed to greater variation in flooding and drying - have been found to be generally more active in terms of biogenic gas production (Kannenberg et al., 2015; Evans and Wallenstein, 2012). This includes marginal zones such as the 
edges of tree islands (HL) and slightly-elevated ridges. These areas experience more seasonal variation in hydrology, and alternate between anaerobic and oxidized conditions. One possible explanation for the greater methanogenic potential at these sites is that they may contain methanogens/microbes which are more adapted to highly variable conditions (Kannenberg et al., 2015; Evans and Wallenstein, 2012; Happell et al., 2003). Tree islands are now widely studied as uniquely important components within the Everglades ridge-and-slough ecosystem, but more research may be needed to better understand the effects of varying hydrology and nutrients on biogenic gas production at their banks (McVoy et al., 2011; Ross et al., 2006).

With climate change projections, there is a greater need to qualify and quantify the unique carbon emissions potential of transitional zones, similar to those of the HL sites of this study. As climate models continue to anticipate an increasing frequency in extreme rain and drought events as a result of climate change, we may expect to see higher variability in the hydrologic cycles of wetlands (Diffenbaugh et al., 2005; IPCC, 2007; Kannenberg et al., 2015). The effects on wetlands could include an increase in the total area that experiences varying cycles of flooding and dry-downs, which could result in greater gaseous carbon emissions, compared to areas which are either continuallyflooded or remain dry year-round. Kannenberg et al. (2015) found that while permanently-saturated soils initially produced the highest levels of $\mathrm{CH}_{4}$, there was a greater overall $\mathrm{CH}_{4}$ production potential among more variable areas, in which soils are seasonally-flooded and dried. Further research and climate change modeling will be needed to more accurately predict the symptoms and effects of climate change in the 
coming century, as they will be inexorably linked to important changes in our planet's ecosystem processes (Haigh et al., 2014).

The analyses of $\mathrm{CO}_{2} / \mathrm{CH}_{4}$ ratios were included in this study as a method of measuring and comparing the potential GHG emissions impact of all sites within LILA over various timeframes. Elevated emissions of $\mathrm{CO}_{2}$ and $\mathrm{CH}_{4}$ each pose a significant risk in terms of atmospheric warming, but these carbon-based gases represent vastly different concentrations within the atmosphere. These two GHGs also possess starkly different potentials for global warming (Table 1). For this reason, it seemed prudent to attempt to qualify the relative global warming potential (GWP) of each site under varying hydrologic conditions, by assessing the respective ratios of $\mathrm{CO}_{2}$ concentrations over $\mathrm{CH}_{4}$ concentrations taken from pore-water samples.

In $\mathrm{M} 4$, the mean $\mathrm{CO}_{2} / \mathrm{CH}_{4}$ ratio (mol:mol) decreased with decreasing elevation; from 43.85 (HH), 24.57 (HL), 14.10 (MR), 5.84 (SS), and finally down to 4.89 (DS). Referring to Table 1 displaying the GWP of these GHGs, $\mathrm{CH}_{4}$ is about 72 times more effective as a warming agent over short-term spans than $\mathrm{CO}_{2}$ (Table 1). Most studies have shown $\mathrm{CO}_{2}$ as representative of the overwhelming majority of gaseous carbon emissions, with $\mathrm{CH}_{4}$ often accounting for about $1 \%$ of total carbon emitted (Hirano et al., 2009). In these examples, the GHG effect of $\mathrm{CO}_{2}$ outweighs that of $\mathrm{CH}_{4}$. For this to remain true in all cases, though, the $\mathrm{CO}_{2} / \mathrm{CH}_{4}$ ratio must necessarily be high; at least more than 72 . If the ratio were around 72 , the GHG effect of $\mathrm{CH}_{4}$ and $\mathrm{CO}_{2}$ would be in a state of equilibrium, at least over short-term periods. However, in M4 throughout this 
study, the mean $\mathrm{CO}_{2} / \mathrm{CH}_{4}$ ratios at the highest site $(\mathrm{HH})$ started at 43.85 and dropped to 4.89 (DS). Furthermore, the average $\mathrm{CO}_{2} / \mathrm{CH}_{4}$ ratio across all sites in $\mathrm{M} 4$ was 22.01, indicating that $\mathrm{CH}_{4}$ had a disproportionately higher $\mathrm{GHG}$ impact relative to $\mathrm{CO}_{2}$ across the elevation spectrum in this re-created Everglades landscape.

\section{CONCLUSIONS}

The focus of this study did not include an analysis of the overall carbon balance at LILA, and therefore, conclusions about the role of this system as a net source or sink of carbon are beyond the scope of work. Without corresponding measurements of the carbon inputs into the system at LILA, larger conclusions about the carbon balance are not possible. However, previous studies have shown a massive decrease in carbon storage across the Everglades, as officially-protected Everglades areas have receded since the late 1800s (Hohner and Dreschel, 2015; Aich et al., 2013; Aich and Dreschel, 2011). This would imply that the Everglades has largely acted as a source of carbon over the last century. Based on the results from this study, $\mathrm{CH}_{4}$ appears to have a disproportionately greater GHG effect across an Everglades landscape, compared to that of $\mathrm{CO}_{2}$. It might seem reasonable, then, to conclude that mid-season drainages could be implemented to decrease the overall GHG potential of wetlands, by reducing the conditions and effects of methanogenesis. However, these ecosystems and their inhabitants are uniquely evolved and dependent on the availability of water, and many Everglades flora and fauna are already under stress from the effects of historical reductions in the amount and flow of 
water throughout the system. It would therefore seem both impractical and ill-advised to alter or inhibit the hydrology of South Florida any further.

At the same time, neglecting to consider the GHG emissions potential of wetlands - especially ones as large as the Everglades - only stands to exacerbate the current climate change problem, by creating a positive feedback loop for future warming. Unabated anthropogenic activities will intensify the effects of climate change, which will impact wetlands in ways that increase GHG production and in turn accelerate global warming. As part of climate change projections, extended drought and altered precipitation patterns pose the greatest imminent threat to the water regime of these systems. Since hydrology drives most biogeochemical interactions in wetlands, it remains critical to assess and adapt our human influences on water flow and availability. In terms of south Florida, this should include evaluating our current water control methods (i.e., draining, rewetting, and redirecting water throughout the region), and attempting to mitigate the effects. As we have already witnessed within the Everglades, disturbing the natural balance of water can have widespread consequences on the ecosystem functions and services of wetlands, especially carbon sequestration. Considering the large carbon storage capacity - and therefore GHG production potential - of these systems, our efforts will have broader implications for the future of the planet and its inhabitants. 


\section{LITERATURE CITED}

Aich, S., \& Dreschel, T. W., 2011. Evaluating Everglades Peat Carbon Loss Using Geospatial Techniques. Florida Scientist 74 (1): 63 - 71.

Aich, S., Dreschel, T.W., Cline, E.A., Sklar, F.H., 2011. The Development of a Geographic Information System (GIS) to Document Research in an Everglades Physical Model, Journal of Environmental Science and Engineering 5: 289 - 302.

Aich, S., Ewe, S.M.L., Gu, B., Dreschel, T.W., 2014. An evaluation of peat loss from an Everglades tree island, Florida, USA. Mires and Peat 14: Art. 2.

Aich, S., McVoy, C.W., Dreschel, T.W., Santamaria, F., 2013. Estimating Soil Subsidence and Carbon Loss in the Everglades Agricultural Area, Florida using Geospatial Techniques. Agriculture, Ecosystems \& Environment, 171: 124-133.

Amador, J.A. \& Jones, R.D., 1995. Carbon Mineralization in Pristine and PhosphorusEnriched Peat Soils of the Florida Everglades. Soil Science, 159: 129 - 141.

Bachoon, D., \& Jones, R., 1992. Potential Rates of Methanogenesis in Sawgrass Marshes with Peat and Marl Soils in the Everglades. Soil Biology \& Biochemistry 24: 21 - 27.

Blodau, C., \& Moore, T.R. 2003. Micro-scale CO2 and CH4 Dynamics in a Peat Soil During Water Fluctuation and Sulfate Pulse. Soil Biology \& Biochemistry 35: 535 - 547.

Bubier, J.L, Moore, T.R., 1993. Methane Emissions from Wetlands in the Midboreal Region of Northern Ontario, Canada. Ecology 74 (8): 2240 - 2254.

Charman, D.J., 2002. Peatlands and Environmental Change. John Wiley and Sons Limited, Chichester.

Comas, X., \& Wright, W., 2014. Investigating Carbon Flux Variability in Subtropical Peat Soils of the Everglades Using Hydrogeophysical Methods. Journal of geophysical research. Biogeosciences 119 (8): 1506 - 1519.

Davis, S.M., Gaiser, E.E., Loftus, W.F., Huffman, A.E., 2005. Southern Marl Prairies Conceptual Ecological Model. Wetlands 25: 821 - 831.

DeLaune, R.D., Reddy, K.R., Richardson, C.J., Megonigal, J.P. (eds.), 2013. Methods in Biogeochemistry of Wetlands. Soil Science Society of America.

Diffenbaugh, N. S., Pal, J. S., Trapp, R. J., Giorgi, F., 2005. Fine-scale processes regulate the response of extreme events to global climate change. Proceedings of the National Academy of Sciences of the United States of America, 102 (44), 15774 - 15778. 
Evans, S.E., Wallenstein, M.D., 2012. Soil Microbial Community Response to Drying and Rewetting Stress: Does Historical Precipitation Regime Matter? Biogeochemistry 109: $101-116$.

Gawlik, D.E., Gronemeyer, P., Powell, R.A., 2002. Habitat-use Patterns of Avian Seed Dispersers in the Central Everglades. In F.H. Sklar and A. van der Valk, eds, Tree Islands of the Everglades. Kluwer Academic Publishers, Dordrecht, Netherlands. pp 445 - 468.

Gorham, E., 1991. Role in the carbon cycle and probable responses to climatic warming. Ecological Applications 1.

Grunfeld, S., \& Brix, H., 1999. Methanogenesis and Methane Emissions: Effects of Water Table, Substrate Type and Presence of Phragmites australis. Aquatic Botany 64: $63-75$.

Happell, J.D., Price, R.M., Top, Z., Swart, P.K., 2003. Evidence for the removal of CFC11, CFC-12, and CFC-113 at the groundwater-surface water interface in the Everglades. Journal of Hydrology 279: 94 - 105.

Haigh, Ivan D., Wahl, T., Rohling, E.J., Price, R.M., Pattiaratchi, C.B., Calafat, F.M., \& Dangendorf, S., 2014. Timescales for Detecting a Significant Acceleration in Sea Level Rise. Nature Communications 5.

Hirano, T., Jauhiainen, J., Inoue, T., Takahashi, H., 2009. Controls on the Carbon Balance of Tropical Peatlands. Ecosystems 12: 873-887.

Hohner, S. M., \& Dreschel, T. W., 2015. Everglades peats: using historical and recent data to estimate predrainage and current volumes, masses and carbon contents. Mires and Peat 16: Art. 1, 1 - 15.

Houghton, R.A., Skole, D.L., 1990. In: B.L. Turner, W.C. Clark, R.W. Kates, J.F. Richards, J.T. Mathews, W.B. Meyer (Eds.). The Earth as Transformed by Human Action. Cambridge University Press: 393 - 408.

Intergovernmental Panel on Climate Change (IPCC). Climate Change 2007: The Physical Science Basis. Contribution of Working Group I to the Fourth Assessment Report of the Intergovernmental Panel on Climate Change (eds. Solomon, S., Qin, D., Manning, M., Chen, Z., Marquis, M., Averyt, K.B., Tignor, M., Miller, H.L.), Cambridge University Press (2007).

Jimenez, K. L., Starr, G., Staudhammer, C.L., Schedlbauer, J.L., Loescher, H.W., Malone, S.L., Oberbauer, S.F., 2012. Carbon dioxide exchange rates from short- and longhydroperiod Everglades freshwater marsh. Geophysical Research. 
Kannenberg, S.A., Dunn, S.T., Ludwig, S.M., Spawn, S.A., Schade, J.D., 2015. Patterns of Potential Methanogenesis Along Soil Moisture Gradients Following Drying and Rewetting in Midwestern Prairie Pothole Wetlands. Wetlands 35: 633 - 640

Kennedy, Donald, and the Editors of Science, 2006. Science Magazine's State of the Planet 2006-2007. Island Press.

Kolbert, Elizabeth, 2011. Enter the Anthropocene - Age of Man. National Geographic, Vol. 219, Issue 3.

Laanbroek, Hendrikus J., 2010. Methane Emission from Natural Wetlands: Interplay Between Emergent Macrophytes and Soil Microbial Processes. A Mini-Review. Annals of Botany 105: $141-153$.

Larsen, L., Aumen, N., Bernhardt, C., Engel, V., Givnish, T., Hagerthey, S., Harvey, J., Leonard, L., McCormick, P., Mcvoy, C., Noe, G., Nungesser, M., Rutchey, K., Sklar, F., Troxler, T., Volin, J., Willard, D., 2011. Recent and Historic Drivers of Landscape Change in the Everglades Ridge, Slough, and Tree Island Mosaic. Critical Reviews in Environmental Science and Technology 41: 344-381.

Light, S.S., Dineen, J.W., 1997. Water Control in the Everglades: A Historical Perspective. In: Davis, S.M., Ogden, J.C., (eds.) Everglades: the ecosystem and its restoration. Boca Raton (FL): St. Lucie Press. pp 47-84.

Ma, Anna, Lu, J.J., Wang, T.H., 2012. Effects of Elevation and Vegetation on Methane Emissions from a Freshwater Estuarine Wetland. Journal of Coastal Research 28 (6): 1319 - 1329.

Malone, Sparkle L., Starr, G., Staudhammer, C.L., \& Ryan, M.G., 2013. Effects of Simulated Drought on the Carbon Balance of Everglades Short-Hydroperiod Marsh. Global Change Biology.

McVoy, C.W., Said, W.P., Obeysekeran, J., Arman, J.V., Dreschel, T.W., 2011. Landscapes and Hydrology of the Pre-Drainage Everglades. Gainesville, FL: University Press of Florida.

Mitsch, W.J., Gosselink, J.G., 2007. Wetlands. John Wiley \& Sons, Inc., Hoboken, 582.

Moore, T.R., \& Knowles, R., 1990. Methane Emissions from Fen, Bog and Swamp Peatlands in Quebec. Biogeochemistry 11 (1): 45 - 61.

Page, S.E., Rieley, J.O., Banks, C.J., 2011. Global and Regional Importance of the Tropical Peatland Carbon Pool. Global Change Biology 17: 798 - 818. 
Reddy, K.R., \& DeLaune, R.D., 2008. Biogeochemistry of Wetlands. CRC Press, Boca Raton, Florida.

Ross, M.S., Mitchell-Bruker, S., Sah, J.P., Stothoff, S., Ruiz, P.L., Reed, D.L., Jayachandran, K., Coultas, C.L., 2006. Interaction of hydrology and nutrient limitation in the ridge and slough landscape of the southern Everglades. Hydrobiologia 569: 37 - 59.

Schedlbauer, J.L., Munyon, J.W., Oberbauer, S.F., Gaiser, E.E., Starr, G., 2012. Controls on Ecosystem Carbon Dioxide Exchange in Short- and Long-Hydroperiod Florida Everglades Freshwater Marshes. Society of Wetland Scientists.

Schroeder, R.S., 2012. Soil carbon dioxide and methane efflux from an Everglades tree island and ridge landscape. M.S. thesis. Florida International University.

Siegel, D.I., Reeve, A.S., Glaser, P.H., \& Romanowicz, E.A., 1994. Climate-driven Flushing of Pore Water in Peatlands. Nature 374: 531 - 533.

Sklar, F.H., and van der Valk, A., 2002. Tree Islands of the Everglades: An Overview. In: F.H. Sklar and A. van der Valk, editors, Tree Islands of the Everglades. Kluwer Academic Publishers, Dordrecht, The Netherlands. pp. 1-18.

Smith, K.A., Ball, T., Conen, F., Dobbie, K.E., Massheder, J., Rey, A., 2003. Exchange of Greenhouse Gases between Soil and Atmosphere: Interactions of Soil Physical Factors and Biological Processes. The European Journal of Soil Science 54: 779-791.

Sorrell, B.K., \& Boon, P.I., 1994. Convective Gas Flow in Eleocharis sphacelata R. Br.: Methane Transport and Release from Wetlands. Aquatic Botany 47: 197 - 212.

Stofella, S. L., M.S. Ross, J.P. Sah, R.M. Price, P. Sullivan, E.A. Cline, and L.J. Scinto. 2010. Survival and Growth Responses of Eight Everglades Tree Species Along an Experimental Hydrological Gradient on Two Tree Island Types. Applied Vegetation Science. 13: 439-449.

Sullivan, P.L., Price, R.M., Ross, M.S., Scinto, L.J., Stoffella, S.L., Cline, E., Dreschel, T.W., Sklar, F.H., 2010. Hydrologic Processes on Tree Islands in the Everglades (Florida, USA): Tracking the Effects of Tree Establishment and Growth. Hydrogeology Journal 19: $367-378$.

Sullivan, P.L., Price, R.M., Miralles-Wilhelm, F., Ross, M.S., Scinto, L.J., Dreschel, T.W., Sklar, F.H., Cline, E., 2012. The Role of Recharge and Evapotranspiration as Hydraulic Drivers of Ion Concentrations in Shallow Groundwater on Everglades Tree Islands, Florida (USA). Hydrological Processes. 
Thomas, C.R., Miao, S.L., Sindhoj, E., 2009. Environmental Factors Affecting Temporal and Spatial Patterns of Soil Redox Potential in Florida Everglades Wetlands. Wetlands 29, 1133-1145.

Torn, M.S., Chapin, F.S., 1993. Environmental and Biotic Controls over Methane Flux from Arctic Tundra. Chemosphere 26: 357 - 368.

U.S. Army Corps of Engineers (USACE) and South Florida Water Management District (SFWMD), 1999. Central and Southern Florida Project Comprehensive Review Study, Final Integrated Feasibility Report and Programmatic Environmental Impact Statement. USACE, Jacksonville District, Jacksonville and SFWMD, West Palm Beach, FL.

United States Environmental Protection Agency (US EPA). Climate Change, Greenhouse Gas Emission Data (2014). Retrieved from: http://epa.gov/climatechange/ghgemissions/

Van der Nat, F., Middelburg, J.J., Van Meteren, D., Wielemakers, A., 1998. Diel Methane Emission Patterns from Scirpus lacustris and Phragmites australis. Biogeochemistry 41: 1 - 22.

Watts, Danielle L., Cohen, M.J., Heffernan, J.B., Osborne, T.Z., 2010. Hydrologic Modification and the Loss of Self-Organized Patterning in the Ridge-Slough Mosaic of the Everglades. Ecosystems 13: 813 - 827.

Webster, K.L., McLaughlin, J.W., Kim, Y., Packalen, M.S., Li, C.S., 2013. Modelling Carbon Dynamics and Response to Environmental Change Along a Boreal Fen Nutrient Gradient. Ecological Modeling.

Wetzel, P.R., A.G. van der Valk, S. Newman, D.E. Gawlik, T. Troxler-Gann, C.A. Coronado-Molina, D.L. Childers, and F.H. Sklar. 2005. Maintaining tree islands in the Florida Everglades: Nutrient redistribution is the key. Front. Ecol. Environ 3: 370 - 376.

Wu, Y., Wang, N., Rutchey, K., 2006. An Analysis of Spatial Complexity of Ridge and Slough Patterns in the Everglades Ecosystem. Ecological Complex 3:183-92. 
Table 1. Global Warming Potential (GWP) of prevalent greenhouse gases (GHGs) in the atmosphere, including $\mathrm{CO}_{2}$ and $\mathrm{CH}_{4}$, with $\mathrm{CO}_{2}$ used as a baseline.

\begin{tabular}{|c|c|c|c|c|c|c|}
\hline \multicolumn{7}{|c|}{$\begin{array}{l}\text { LIFETIME AND GLOBAL WARMING POTENTIAL OF } \\
\text { HUMAN-GENERATED GREENHOUSE GASES }\end{array}$} \\
\hline Gas & $\mathrm{CO}_{2}$ & $\mathrm{CH}_{4}$ & $\mathrm{~N}_{2} \mathrm{O}$ & CFC-11 & CFC-12 & HCFC-22 \\
\hline Lifetime years & Multiple & 12 & 114 & 45 & 100 & 12 \\
\hline \multicolumn{7}{|c|}{ Global warming potential } \\
\hline 20 years & 1 & 72 & 289 & 6,730 & 11,000 & 5,160 \\
\hline 100 years & 1 & 25 & 298 & 4,750 & 10,900 & 1,810 \\
\hline 500 years & 1 & 8 & 153 & 1,620 & 5,200 & 549 \\
\hline
\end{tabular}

(c) 2009 Pearson Education, Inc. 


\section{CHANGES IN GREENHOUSE GASES: \\ ICE-CORE AND MODERN DATA}
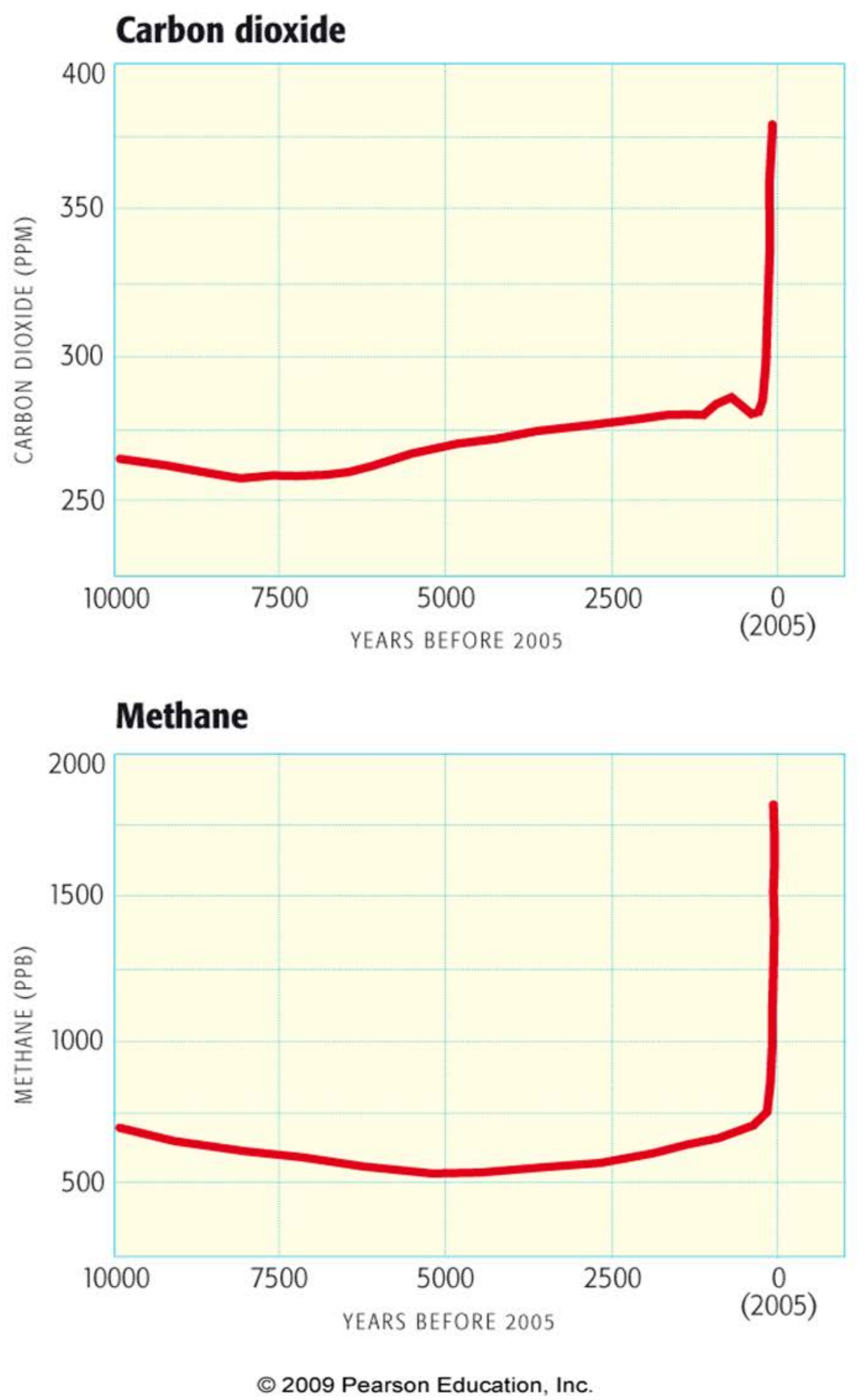

Figure 1. Changes in atmospheric concentrations of $\mathrm{CO}_{2}$ and $\mathrm{CH}_{4}$ (from ice core data), with dramatic increases coinciding with recent industrial activity. 


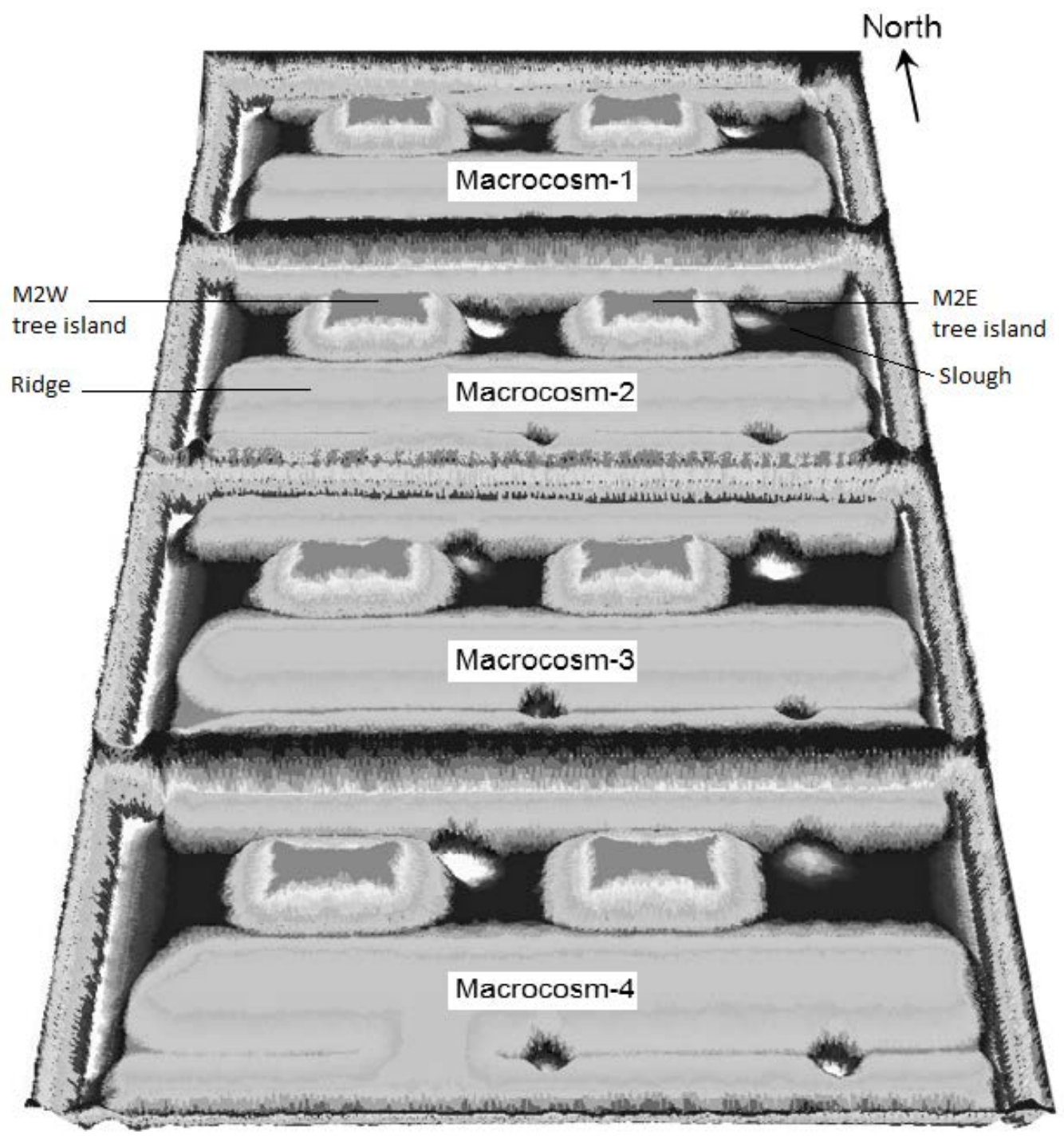

Figure 2. LILA macrocosms and constructed landscape components of varying elevations, modified from Aich et al., 2011. 


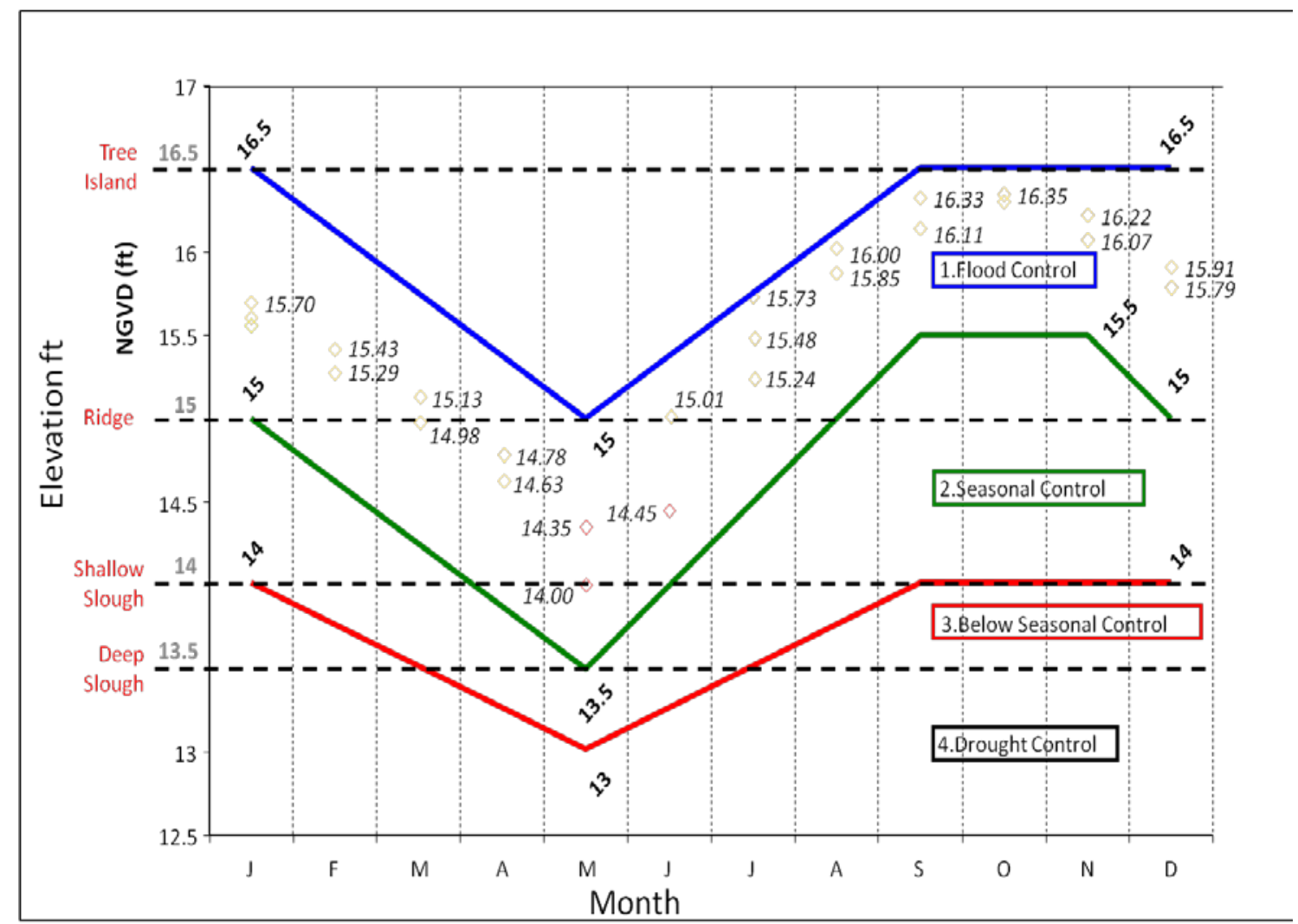

Figure 3. Operational hydrograph at LILA, with elevations given in standardized $\mathrm{ft}$ NGVD (National Geodetic Vertical Datum). Stage (water level) is controlled and adjusted biweekly in each individual macrocosm according to historical seasonal averages, represented by the green line. Other experimental hydrographs include controls for flood conditions (blue line) and below-seasonal levels (red line). During the summer 2015, water levels dropped below these lower standards, falling into a Drought category. 


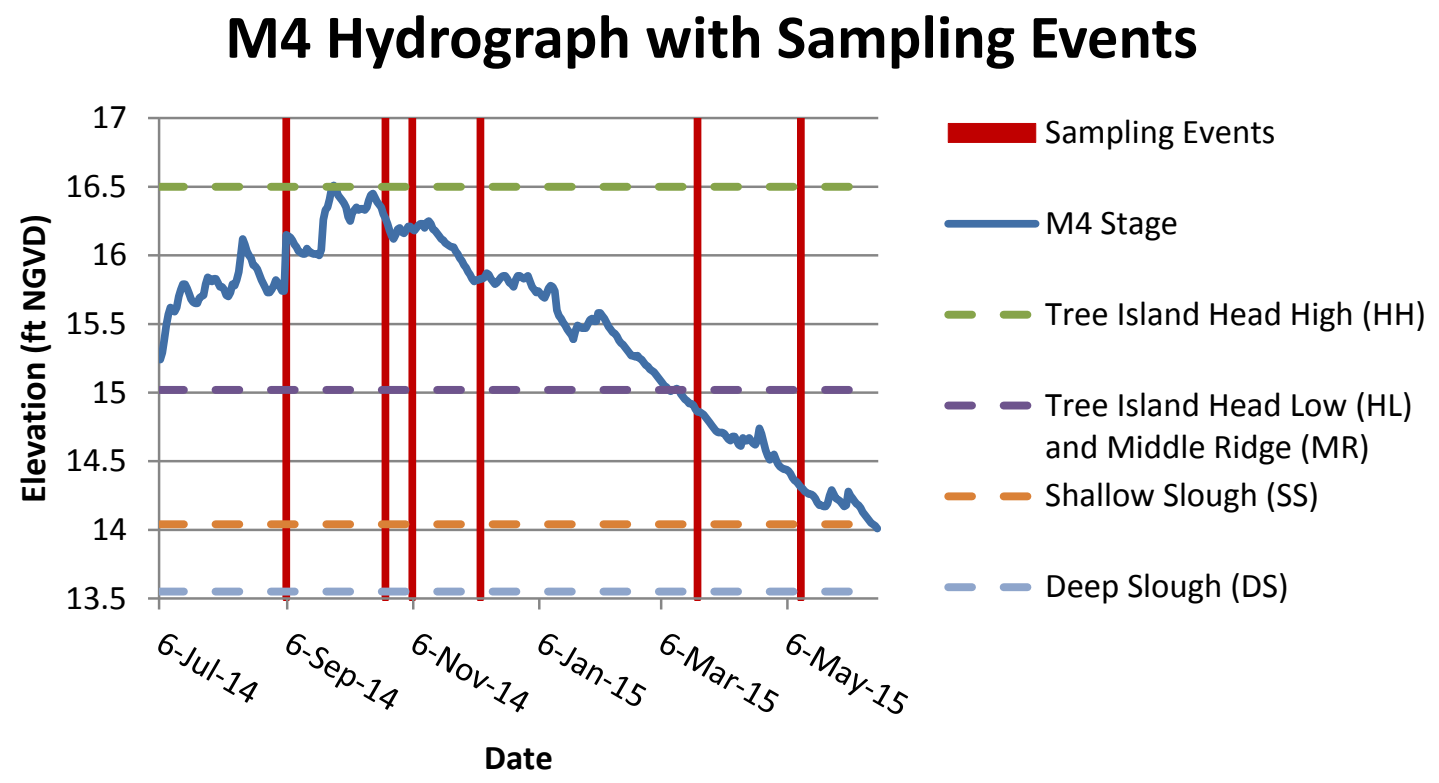

Figure 4. LILA M4 hydrograph from July 2014 until June 2015, including six sampling iterations, from September 2014 until May 2015. Elevation is given in feet NGVD, including relative elevations of all sites featured in M4: Tree Island Head High $(\mathrm{HH})$ at $16.5 \mathrm{ft}$ NGVD, Tree Island Head Low (HL) at $15 \mathrm{ft}$ NGVD, Middle Ridge (MR) also at $15 \mathrm{ft}$ NGVD, Shallow Slough (SS) at $14 \mathrm{ft}$ NGVD, and Deep Slough (DS) at $13.5 \mathrm{ft}$ NGVD. 


\section{LILA Hydrograph for M4 and M1}

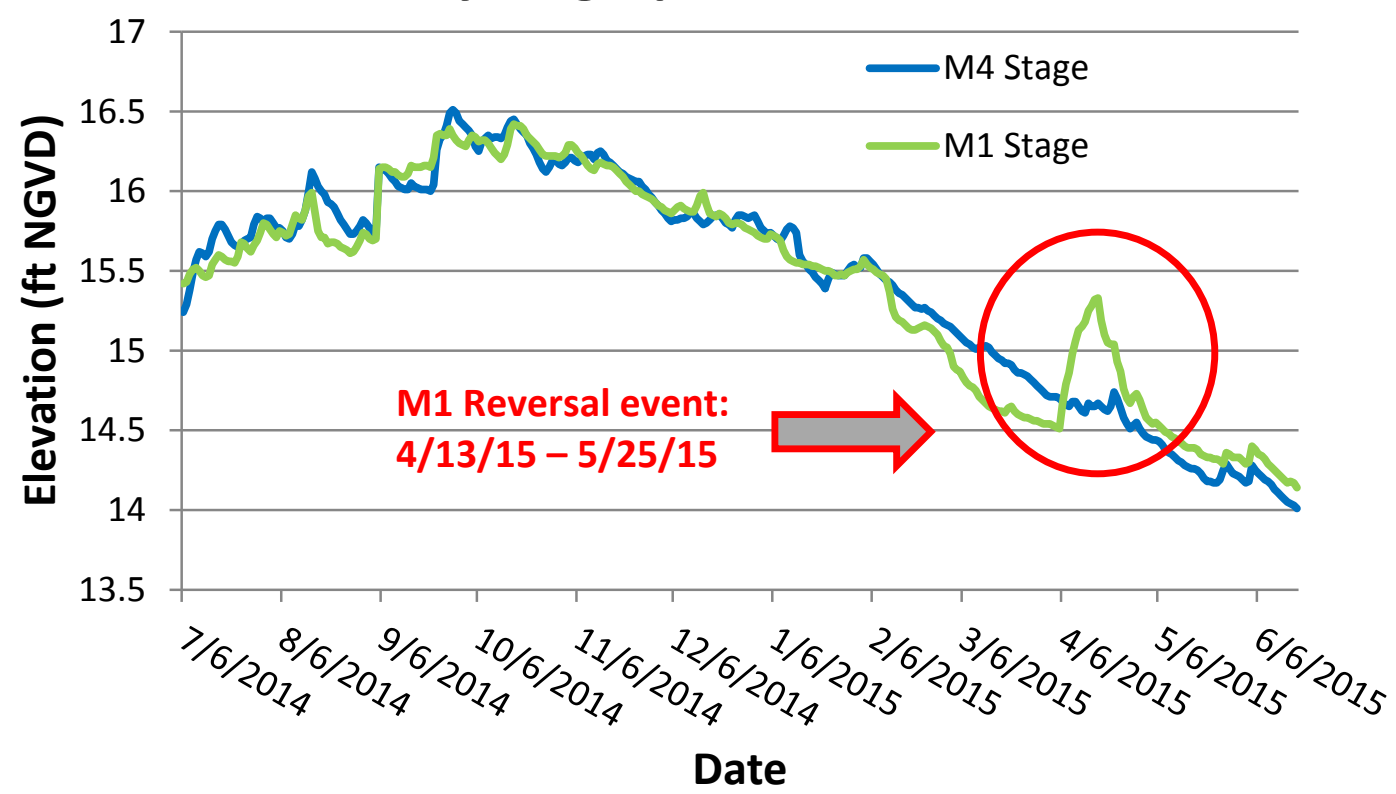

Figure 5. LILA hydrograph for M4 and M1, from July 2014 until June 2015. Elevations are given in $\mathrm{ft}$ NGVD. All stage values came from the South Florida Water Management District's (SFWMD) DBHYDRO database, and were quality-assured and qualitycontrolled (QAQC) by SFWMD in July 2015. Water levels were planned to be raised in June 2015, but an atypical drought in summer of 2015 prevented enough water from being available to increase stages according to the operational hydrograph. 


\section{M1 Hydrograph with Sampling Events}

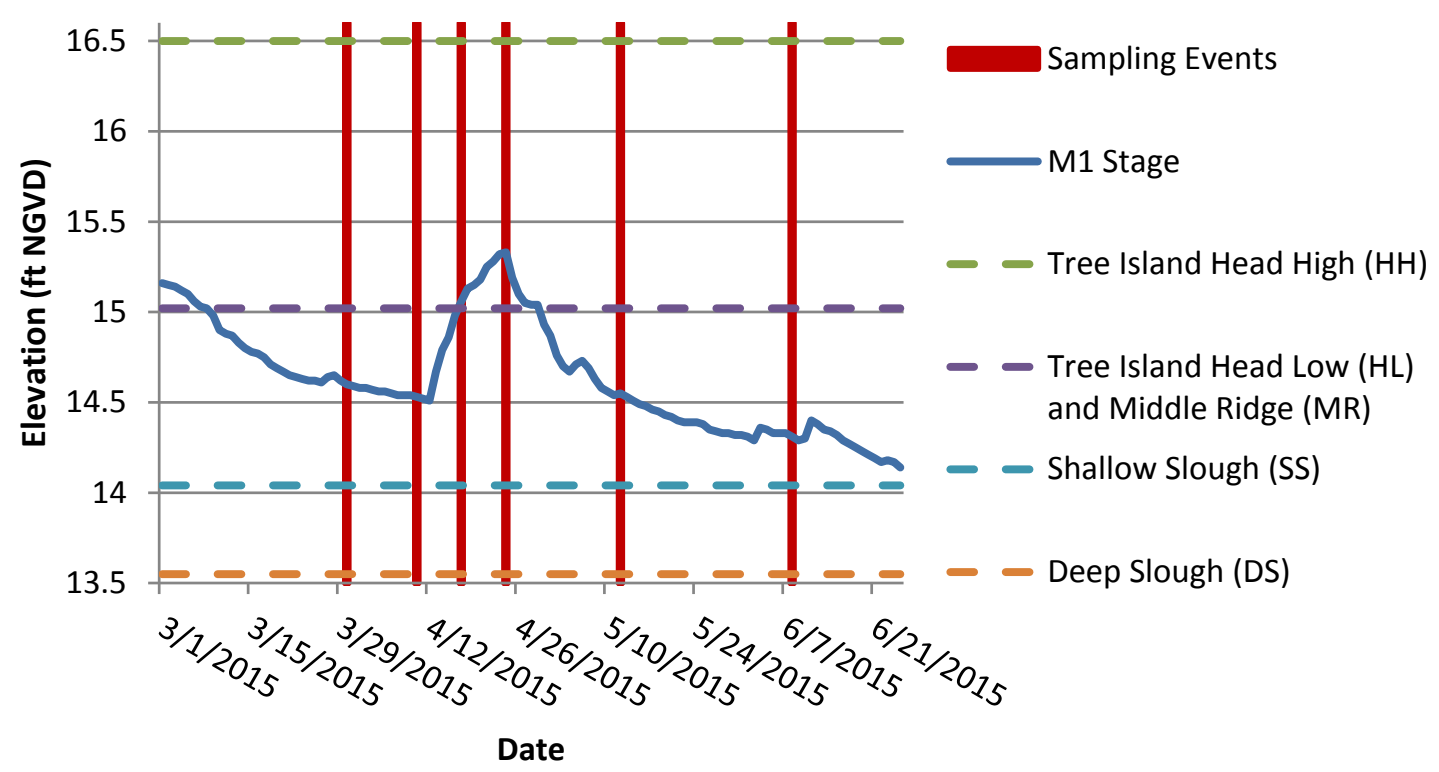

Figure 6. LILA M1 hydrograph from March 2015 until June 2015, including six sampling iterations, from April 2015 to May 2015. Data collection was scheduled to include sampling during periods that were hydrologically-similar to those used in M4: preflooding, mid-flood, at-peak levels, mid-recession, and post-recession. Elevation is given in feet NGVD, and includes relative elevations of all sites featured in M1 (constructed at equal elevations to those in M4). 


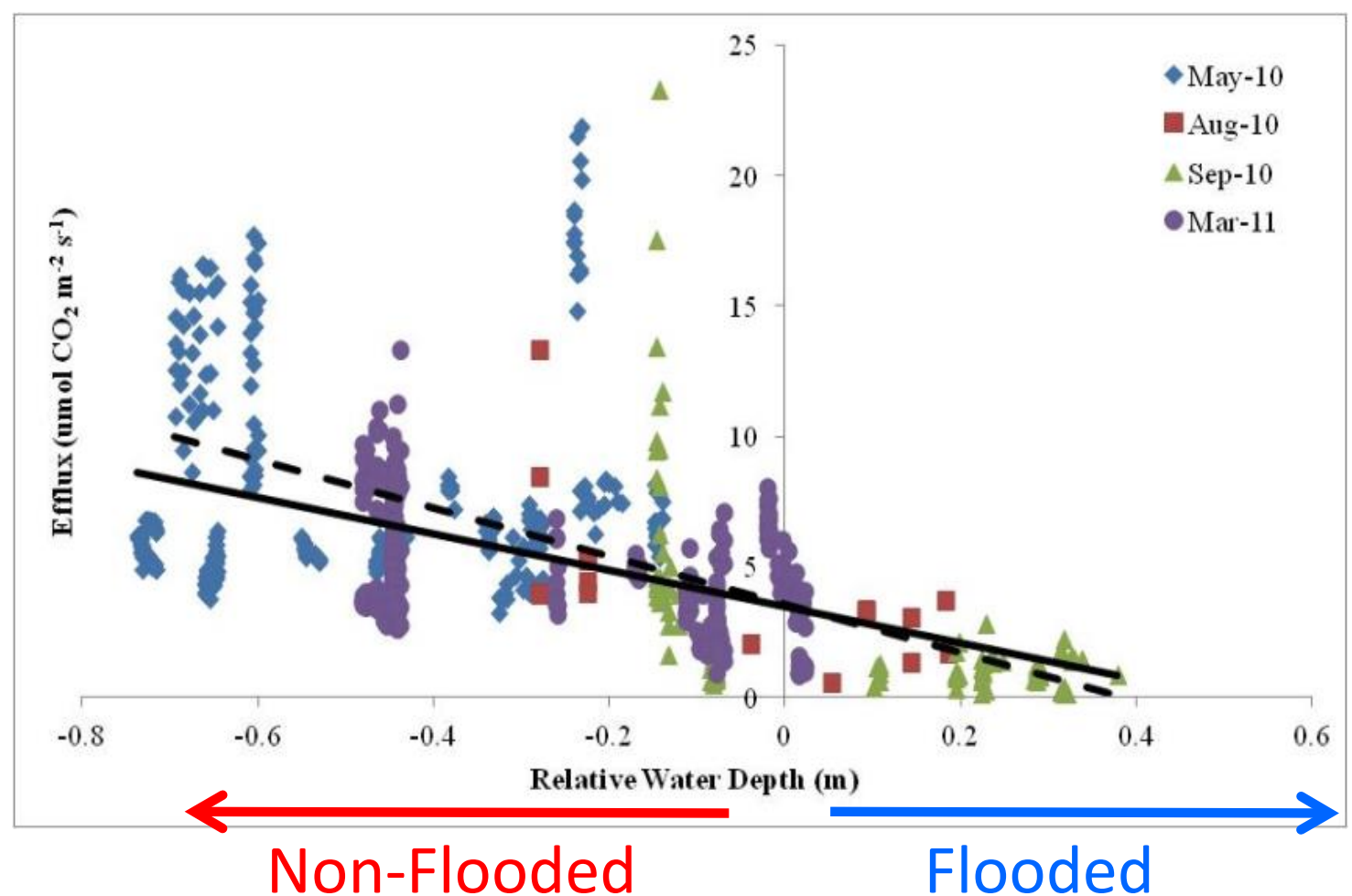

Figure 7. Efflux rates of $\mathrm{CO}_{2}$ across relative water depth, shown in a previous LILA study (Schroeder, 2012). 


\section{Cross-section of a macrocosm with Sippers installed}

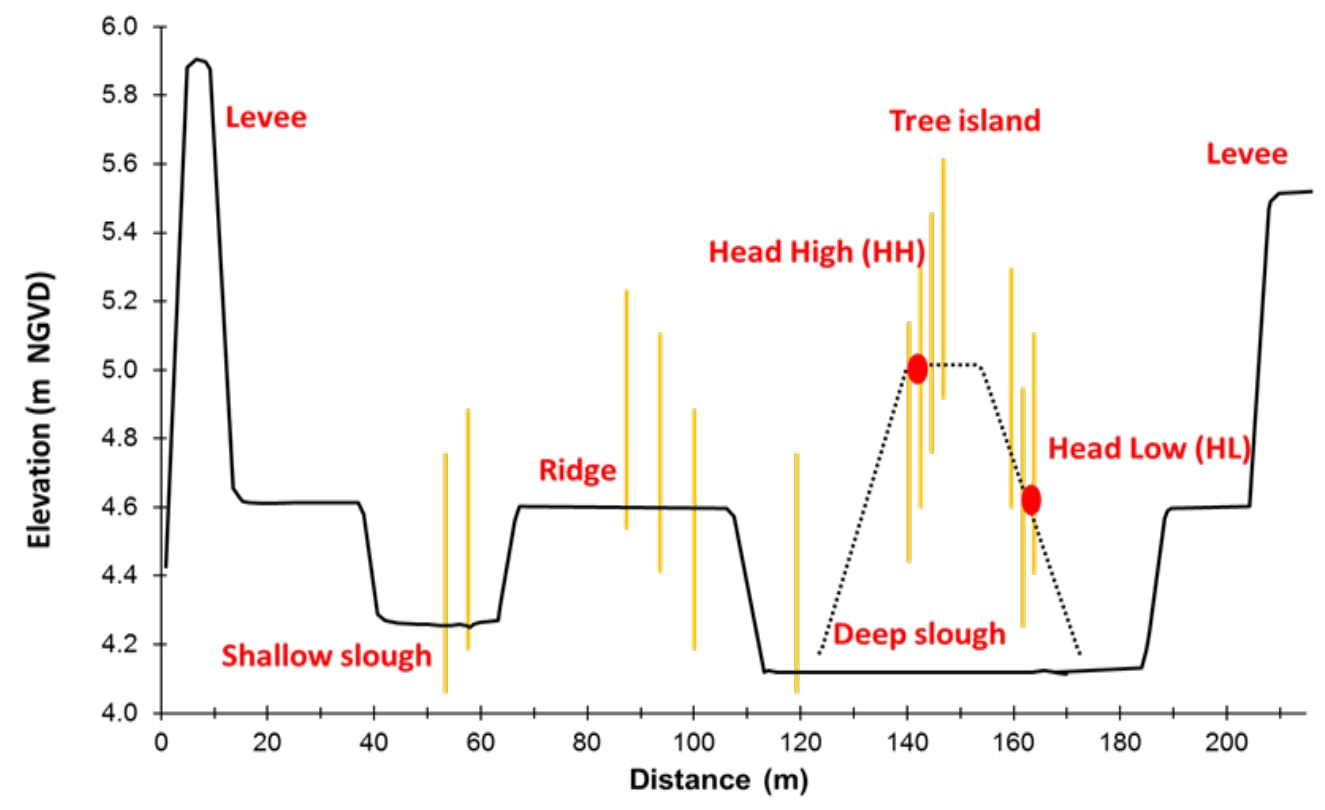

Figure 8. Relative elevations of constructed landscape features within a LILA macrocosm, including approximate depictions of sipper tubes installed throughout each site at varying depths. To compare relative depths, the soil surface of the deep slough (DS) was set as a baseline elevation, with other depths compared relative to this low point. 


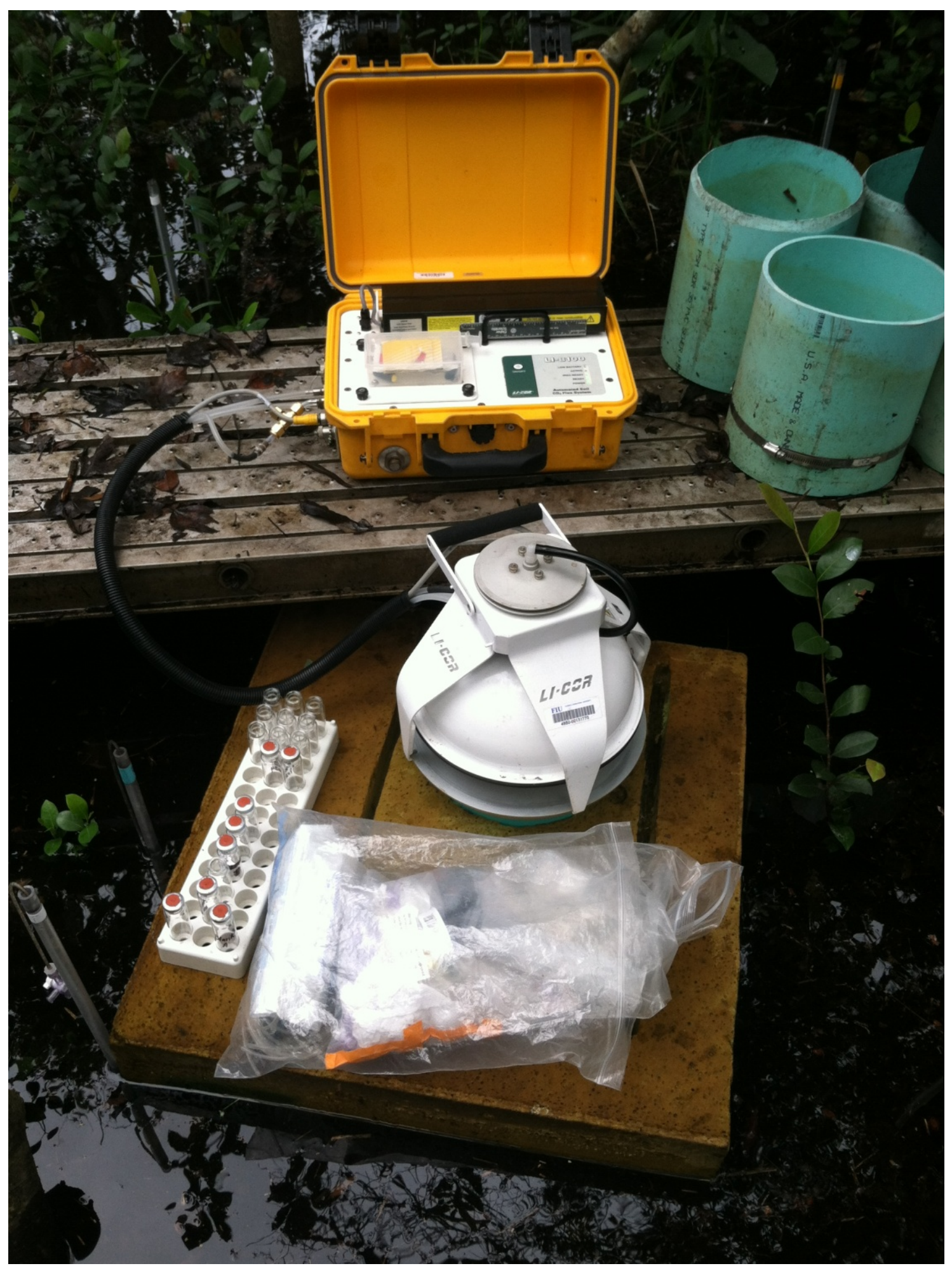

Figure 9. Photo of LICOR LI-8100 IRGA sampling above flooded soils, with installed pore-water sipper tubes also featured to the left of the floating platform and IRGA. 


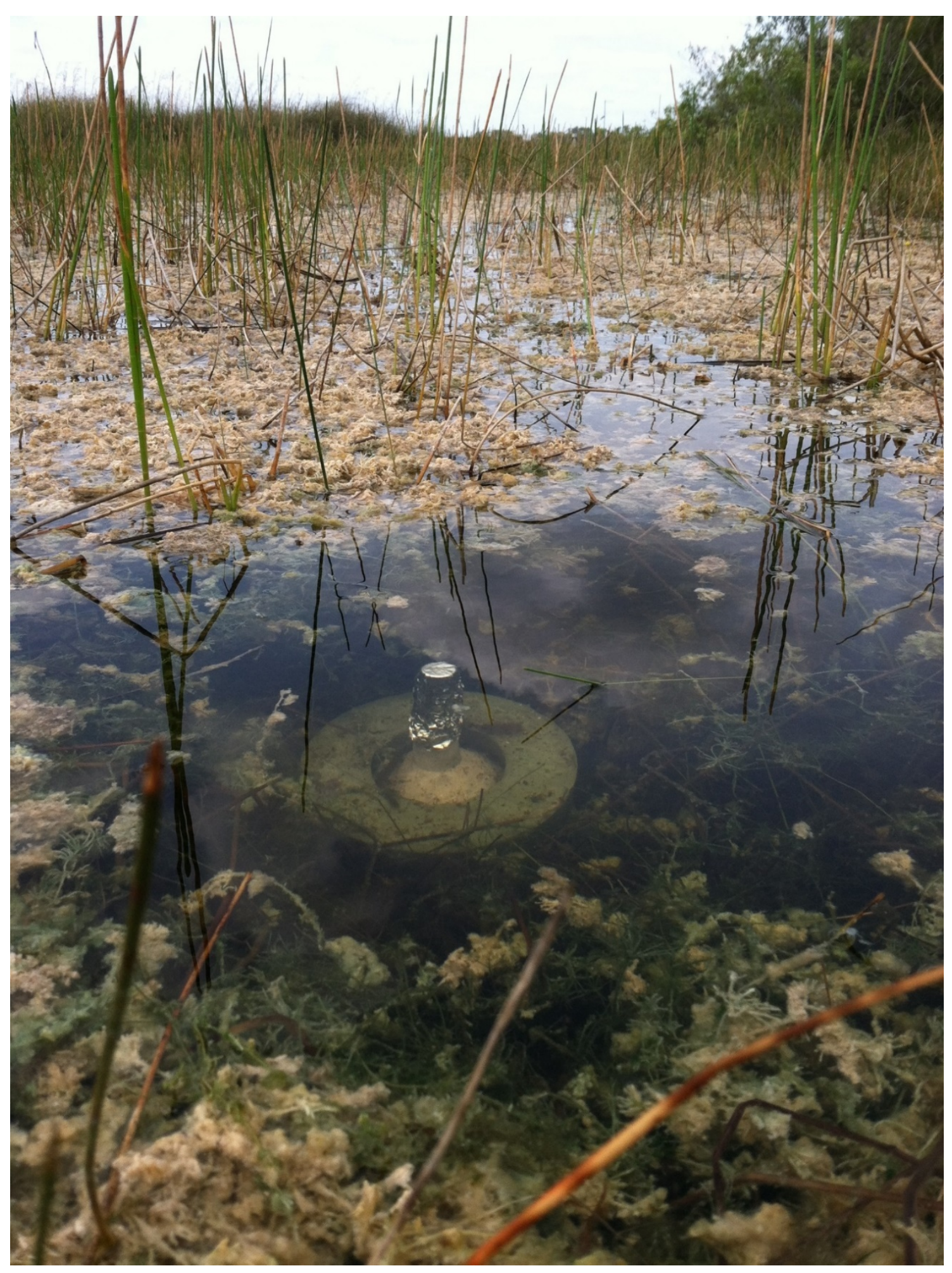

Figure 10. Photo of a Gas Trap installed within a shallow slough in M4. 
Table 2. Descriptive results from ANOVAs of pore-water sipper data in M4.

\begin{tabular}{|c|c|c|c|c|c|c|c|c|c|}
\hline \multicolumn{10}{|c|}{ Descriptives $^{a}$} \\
\hline & & \multirow[b]{2}{*}{$\mathbf{N}$} & \multirow[b]{2}{*}{ Mean } & \multirow[b]{2}{*}{ Std. Deviation } & \multirow[b]{2}{*}{ Std. Error } & \multicolumn{2}{|c|}{ Mean } & \multirow[b]{2}{*}{ Minimum } & \multirow[b]{2}{*}{ Maximum } \\
\hline & & & & & & Lower Bound & Upper Bound & & \\
\hline \multirow[t]{6}{*}{ CH4 umol L-1 } & $\mathrm{HH}$ & 72 & 2190.589 & 3443.349 & 405.803 & 1381.441 & 2999.736 & 13.096 & 12720.000 \\
\hline & HL & 59 & 2461.315 & 3640.438 & 473.945 & 1512.611 & 3410.018 & 24.713 & 13248.000 \\
\hline & MR & 68 & 3178.209 & 4939.528 & 599.006 & 1982.588 & 4373.829 & 23.520 & 17864.000 \\
\hline & SS & 48 & 3650.656 & 5329.098 & 769.189 & 2103.247 & 5198.065 & 108.760 & 21920.000 \\
\hline & DS & 24 & 4455.664 & 6776.006 & 1383.146 & 1594.408 & 7316.921 & 221.200 & 22712.000 \\
\hline & Total & 271 & 2956.552 & 4624.061 & 280.892 & 2403.535 & 3509.568 & 13.096 & 22712.000 \\
\hline \multirow[t]{6}{*}{$\mathrm{CO} 2 \mathrm{mmol} \mathrm{L-1}$} & $\mathrm{HH}$ & 72 & 15.073 & 15.791 & 1.861 & 11.362 & 18.784 & 1.447 & 49.040 \\
\hline & HL & 59 & 14.897 & 15.762 & 2.052 & 10.789 & 19.004 & 0.595 & 42.720 \\
\hline & MR & 68 & 8.215 & 9.974 & 1.210 & 5.800 & 10.629 & 0.707 & 34.356 \\
\hline & SS & 48 & 10.358 & 11.478 & 1.657 & 7.025 & 13.691 & 1.014 & 37.256 \\
\hline & DS & 24 & 9.755 & 11.213 & 2.289 & 5.021 & 14.490 & 2.146 & 35.120 \\
\hline & Total & 271 & 12.008 & 13.644 & 0.829 & 10.376 & 13.639 & 0.595 & 49.040 \\
\hline \multirow[t]{6}{*}{$\mathrm{CO} 2 / \mathrm{CH} 4$} & HH & 72 & 43.858 & 86.521 & 10.197 & 23.527 & 64.189 & 3.028 & 567.294 \\
\hline & HL & 59 & 24.577 & 43.675 & 5.686 & 13.195 & 35.959 & 1.926 & 217.295 \\
\hline & MR & 68 & 14.107 & 33.538 & 4.067 & 5.989 & 22.225 & 0.982 & 185.884 \\
\hline & SS & 48 & 5.847 & 5.383 & 0.777 & 4.284 & 7.410 & 1.317 & 26.236 \\
\hline & DS & 24 & 4.899 & 4.822 & 0.984 & 2.862 & 6.935 & 1.447 & 22.412 \\
\hline & Total & 271 & 22.012 & 53.678 & 3.261 & 15.593 & 28.432 & 0.982 & 567.294 \\
\hline
\end{tabular}

a. Macrocosm = M4 
Table 3. Descriptive results from ANOVAs of pore-water sipper data taken in M1.

\begin{tabular}{|c|c|c|c|c|c|c|c|c|c|}
\hline \multicolumn{10}{|c|}{ Descriptives $^{a}$} \\
\hline & & \multirow[b]{2}{*}{$\mathbf{N}$} & \multirow[b]{2}{*}{ Mean } & \multirow[b]{2}{*}{ Std. Deviation } & \multirow[b]{2}{*}{ Std. Error } & \multicolumn{2}{|c|}{ Mean } & \multirow[b]{2}{*}{ Minimum } & \multirow[b]{2}{*}{ Maximum } \\
\hline & & & & & & Lower Bound & Upper Bound & & \\
\hline \multirow[t]{6}{*}{ CH4 umol L-1 } & $\mathrm{HH}$ & 31 & 569.641 & 861.462 & 154.723 & 253.654 & 885.627 & 11.260 & 3259.200 \\
\hline & HL & 29 & 138.588 & 156.664 & 29.092 & 78.996 & 198.180 & 19.200 & 606.800 \\
\hline & MR & 33 & 264.608 & 589.522 & 102.623 & 55.573 & 473.643 & 14.640 & 3428.000 \\
\hline & SS & 18 & 1520.369 & 1058.805 & 249.563 & 993.837 & 2046.900 & 383.600 & 3504.000 \\
\hline & DS & 18 & 618.544 & 621.269 & 146.434 & 309.594 & 927.493 & 60.600 & 2680.000 \\
\hline & Total & 129 & 534.189 & 811.544 & 71.452 & 392.808 & 675.570 & 11.260 & 3504.000 \\
\hline \multirow[t]{6}{*}{ CO2 mmol L-1 } & $\mathrm{HH}$ & 31 & 10.361 & 6.833 & 1.227 & 7.854 & 12.867 & 4.308 & 30.840 \\
\hline & HL & 29 & 7.081 & 4.112 & 0.764 & 5.517 & 8.645 & 2.564 & 18.706 \\
\hline & MR & 33 & 6.075 & 4.208 & 0.733 & 4.583 & 7.567 & 0.619 & 17.012 \\
\hline & SS & 18 & 4.504 & 2.238 & 0.528 & 3.391 & 5.617 & 1.578 & 7.842 \\
\hline & DS & 18 & 6.316 & 5.196 & 1.225 & 3.732 & 8.900 & 1.526 & 22.776 \\
\hline & Total & 129 & 7.145 & 5.215 & 0.459 & 6.237 & 8.054 & 0.619 & 30.840 \\
\hline \multirow[t]{6}{*}{$\mathrm{CO} 2 / \mathrm{CH} 4$} & $\mathrm{HH}$ & 31 & 142.498 & 194.283 & 34.894 & 71.234 & 213.761 & 2.392 & 797.869 \\
\hline & HL & 29 & 166.773 & 162.294 & 30.137 & 105.040 & 228.507 & 6.753 & 647.813 \\
\hline & MR & 33 & 83.334 & 94.238 & 16.405 & 49.919 & 116.750 & 2.784 & 386.139 \\
\hline & SS & 18 & 4.945 & 3.556 & 0.838 & 3.177 & 6.713 & 0.659 & 9.917 \\
\hline & DS & 18 & 18.717 & 13.614 & 3.209 & 11.947 & 25.488 & 0.876 & 48.779 \\
\hline & Total & 129 & 96.355 & 143.389 & 12.625 & 71.375 & 121.335 & 0.659 & 797.869 \\
\hline
\end{tabular}


$\mathrm{M} 4 \mathrm{CH}_{4}$ Concentrations Across Sites

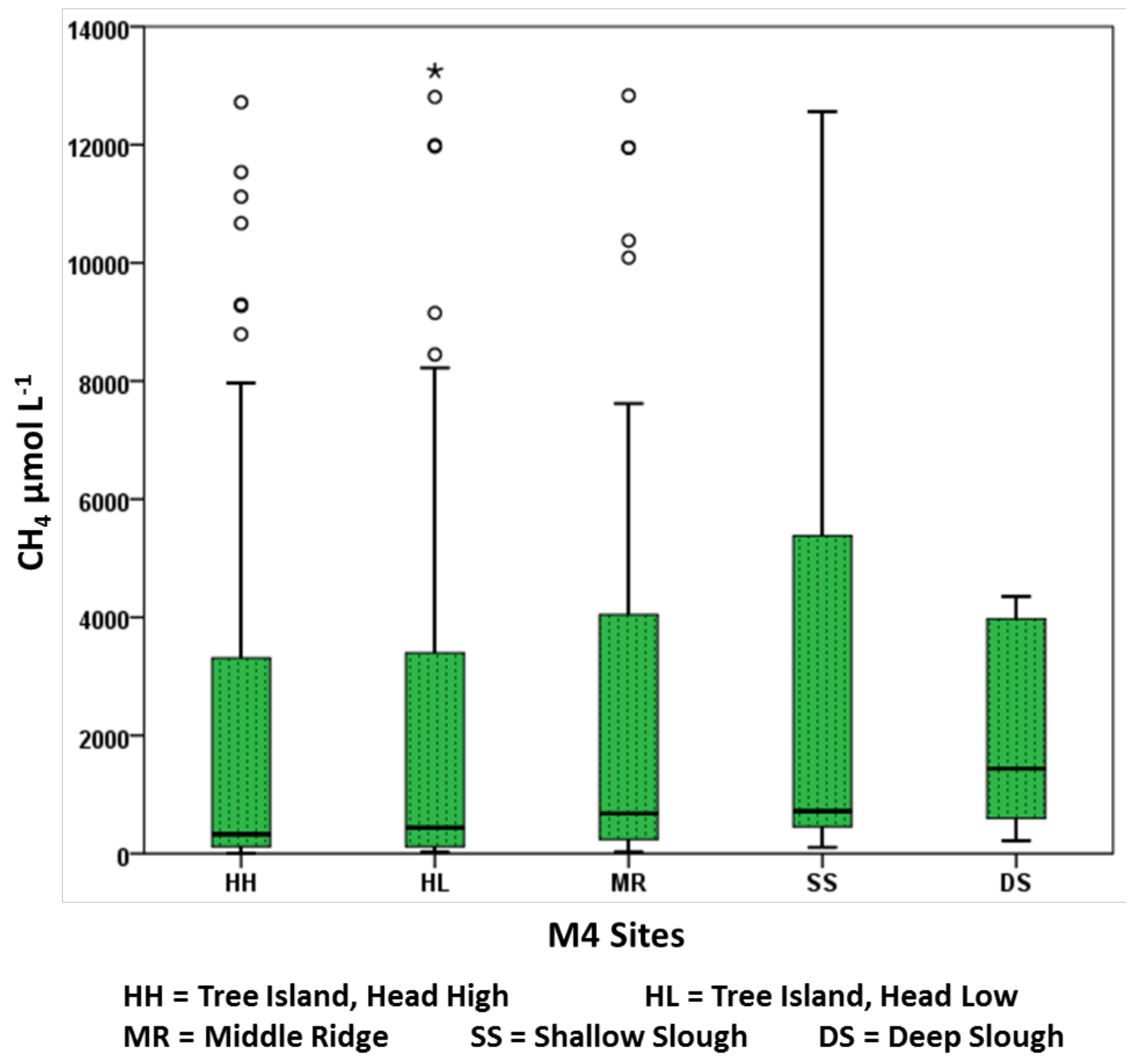

Figure 11. Boxplot of $\mathrm{CH}_{4}$ concentrations in mmol L-1 taken from pore-water sippers installed in M4 across all sites: Tree Island Head High (HH), Tree Island Head Low (HL), Middle Ridge (MR), Shallow Slough (SS), and Deep Slough (DS), listed left-to-right from highest to lowest site elevation (except for the HL and MR sites which are situated at the same elevation). Circles outside of box-and-whisker plots represent outliers, while stars represent extreme outliers. 


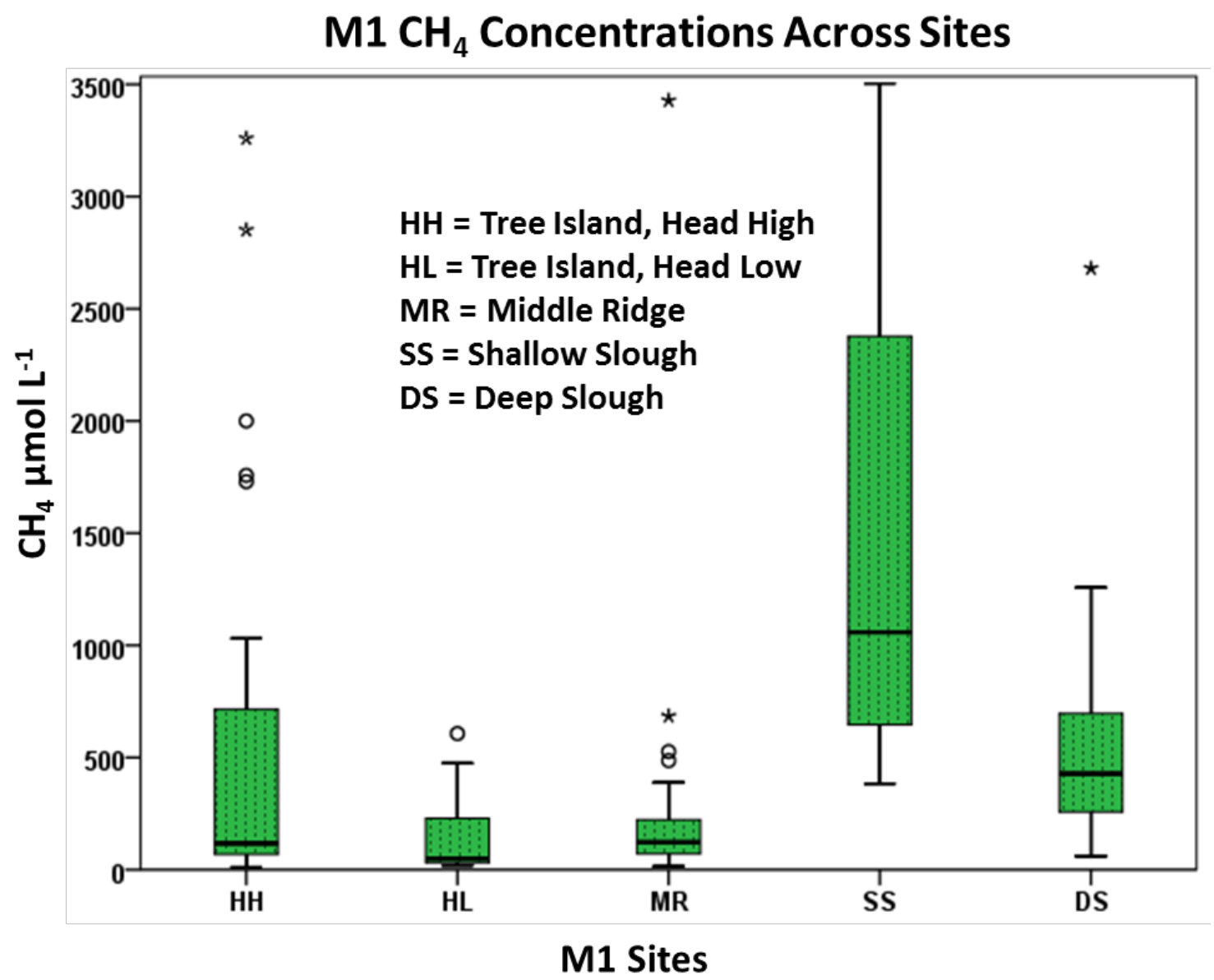

Figure 12. Boxplot of $\mathrm{CH}_{4}$ concentrations in $\mu \mathrm{mol} \mathrm{L} \mathrm{L}^{-1}$ across all M1 sites (HH, HL, MR, SS, and DS), listed left-to-right from highest to lowest site elevation (except for HL and MR). Circles outside of plots represent outliers, and stars represent extreme outliers. 


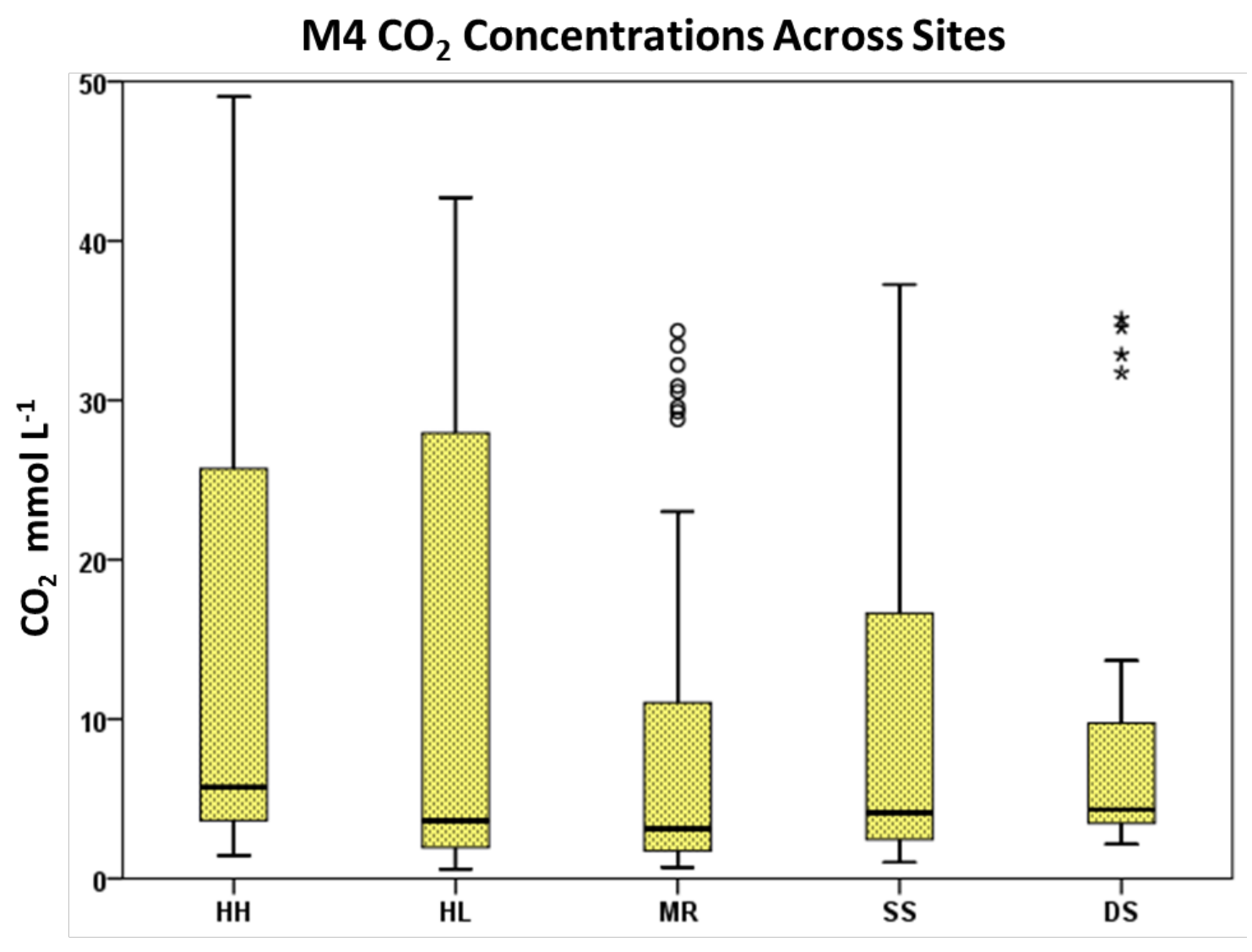

M4 Sites

$$
\begin{aligned}
& \mathrm{HH}=\text { Tree Island, Head High } \quad H L=\text { Tree Island, Head Low } \\
& \text { MR = Middle Ridge } \quad \text { SS = Shallow Slough } \quad \text { DS = Deep Slough }
\end{aligned}
$$

Figure 13. Boxplot of $\mathrm{CO}_{2}$ concentrations in $\mathrm{mmol} \mathrm{L}^{-1}$ from pore-water sippers in $\mathrm{M} 4$ across all sites (HH, HL, MR, SS, DS), which are listed left-to-right from highest to lowest site elevation (except for HL and MR sites which are situated at the same elevation). Circles outside of box-and-whisker plots represent outliers, and stars represent extreme outliers. 


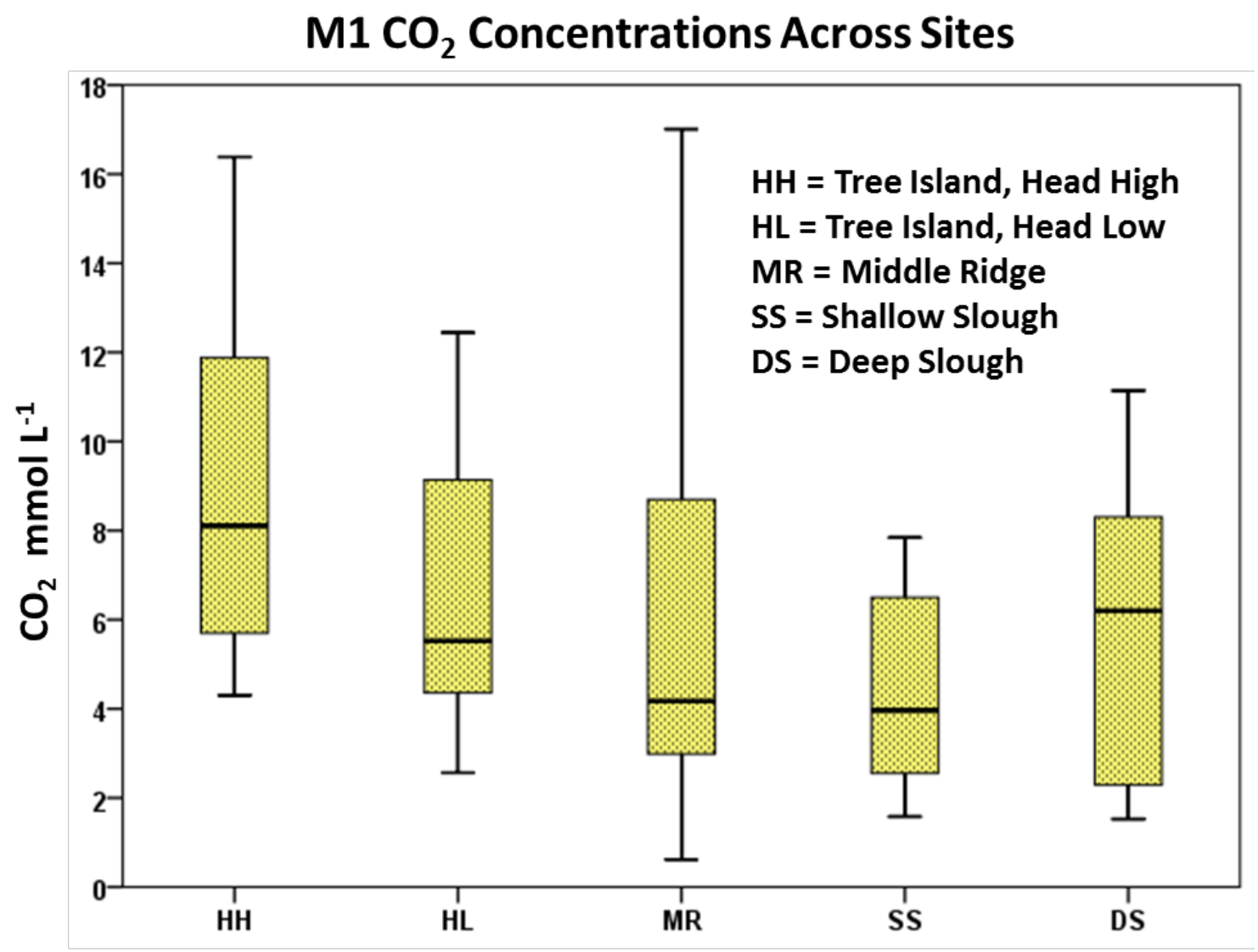

M1 Sites

Figure 14. Boxplot of $\mathrm{CO}_{2}$ concentrations in mmol L ${ }^{-1}$ across $\mathrm{M} 1$ sites (HH, HL, MR, SS, DS), listed left-to-right from highest to lowest site elevation (except for HL and MR). Circles outside plots represent outliers, and stars represent extreme outliers. 
Table 4. Correlations of variables in M4 from September 2014 to June 2015.

Correlations

\begin{tabular}{|c|c|c|c|c|c|c|c|}
\hline & & LILA Stage & Inundation $(\mathrm{cm})$ & Days Flooded & Redox $(m V)$ & $\mathrm{CH} 4$ (umols L-1) & CO2 (mmols L-1) \\
\hline Inundation (cm) & $\begin{array}{l}\text { Pearson Correlation } \\
\text { Sig. (2-tailed) } \\
\text { N }\end{array}$ & $\begin{array}{r}.535^{* *} \\
.000 \\
271\end{array}$ & & & & & \\
\hline Days Flooded & $\begin{array}{l}\text { Pearson Correlation } \\
\text { Sig. (2-tailed) } \\
\mathrm{N}\end{array}$ & $\begin{array}{r}-.291^{* *} \\
.000 \\
271\end{array}$ & $\begin{array}{c}.538^{\star *} \\
.000 \\
271\end{array}$ & & & & \\
\hline Redox (mV) & $\begin{array}{l}\text { Pearson Correlation } \\
\text { Sig. (2-tailed) } \\
\mathrm{N}\end{array}$ & $\begin{array}{r}-.405^{* *} \\
.000 \\
271 \\
\end{array}$ & $\begin{array}{r}-.168^{* *} \\
.006 \\
271 \\
\end{array}$ & $\begin{array}{c}.218^{\star *} \\
.000 \\
271 \\
\end{array}$ & & & \\
\hline $\mathrm{CH} 4$ umol L-1 & $\begin{array}{l}\text { Pearson Correlation } \\
\text { Sig. (2-tailed) } \\
\mathrm{N}\end{array}$ & $\begin{array}{r}.425^{* *} \\
.000 \\
271 \\
\end{array}$ & $\begin{array}{c}.376^{\star \star} \\
.000 \\
271 \\
\end{array}$ & $\begin{array}{l}.047 \\
.445 \\
271 \\
\end{array}$ & $\begin{array}{r}.030 \\
.620 \\
271 \\
\end{array}$ & & \\
\hline CO2 mmol L-1 & $\begin{array}{l}\text { Pearson Correlation } \\
\text { Sig. (2-tailed) } \\
\mathrm{N}\end{array}$ & $\begin{array}{r}.420^{* *} \\
.000 \\
271 \\
\end{array}$ & $\begin{array}{c}.205^{\star *} \\
.001 \\
271 \\
\end{array}$ & $\begin{array}{r}-.126^{*} \\
.038 \\
271 \\
\end{array}$ & $\begin{array}{l}.084 \\
.168 \\
271 \\
\end{array}$ & $\begin{array}{l}.781^{\star \star} \\
.000 \\
271 \\
\end{array}$ & \\
\hline $\mathrm{CO} 2 / \mathrm{CH} 4$ & $\begin{array}{l}\text { Pearson Correlation } \\
\text { Sig. (2-tailed) } \\
\mathrm{N}\end{array}$ & $\begin{array}{r}-.440^{* *} \\
.000 \\
271\end{array}$ & $\begin{array}{r}-.415^{* *} \\
.000 \\
271\end{array}$ & $\begin{array}{r}-.177^{\star *} \\
.003 \\
271 \\
\end{array}$ & $\begin{array}{c}.138^{*} \\
.023 \\
271\end{array}$ & $\begin{array}{r}-.215^{\star *} \\
.000 \\
271\end{array}$ & $\begin{array}{r}-.139^{*} \\
.022 \\
271\end{array}$ \\
\hline
\end{tabular}

Correlation is significant at the 0.05 level (2-tailed)

${ }^{* *}$. Correlation is significant at the 0.01 level (2-tailed). Macrocosm $=$ M4 
Table 5. Correlations for M1 variables during a hydrologic reversal from April 2015 until June 2015.

Correlations

\begin{tabular}{|c|c|c|c|c|c|c|c|}
\hline & & LILA Stage & Inundation $(\mathrm{cm})$ & Days Flooded & Redox $(\mathrm{mV})$ & $\mathrm{CH} 4$ (umols L-1) & CO2 (mmols L-1) \\
\hline Inundation (cm) & $\begin{array}{l}\text { Pearson Correlation } \\
\text { Sig. (2-tailed) } \\
\mathrm{N}\end{array}$ & $\begin{array}{r}.323^{\star \star} \\
0 \\
129 \\
\end{array}$ & & & & & \\
\hline Days Flooded & $\begin{array}{l}\text { Pearson Correlation } \\
\text { Sig. (2-tailed) } \\
\mathrm{N}\end{array}$ & $\begin{array}{r}-.211 * \\
0.017 \\
129 \\
\end{array}$ & $\begin{array}{r}.280 * * \\
0.001 \\
129 \\
\end{array}$ & & & & \\
\hline Redox (mV) & $\begin{array}{l}\text { Pearson Correlation } \\
\text { Sig. (2-tailed) } \\
\mathrm{N}\end{array}$ & $\begin{array}{r}0.152 \\
0.086 \\
129 \\
\end{array}$ & $\begin{array}{r}-.177^{\star} \\
0.045 \\
129 \\
\end{array}$ & $\begin{array}{r}-.423^{* \star} \\
0 \\
129 \\
\end{array}$ & & & \\
\hline $\mathrm{CH} 4$ umol L-1 & $\begin{array}{l}\text { Pearson Correlation } \\
\text { Sig. (2-tailed) } \\
\text { N }\end{array}$ & $\begin{array}{r}-0.083 \\
0.351 \\
129 \\
\end{array}$ & $\begin{array}{r}-0.076 \\
0.394 \\
129 \\
\end{array}$ & \begin{tabular}{r|}
$.180 *$ \\
0.041 \\
129 \\
\end{tabular} & $\begin{array}{r}-.336^{\star *} \\
0 \\
129\end{array}$ & & \\
\hline $\mathrm{CO} 2 \mathrm{mmol} \mathrm{L}-1$ & $\begin{array}{l}\text { Pearson Correlation } \\
\text { Sig. (2-tailed) } \\
\mathrm{N}\end{array}$ & $\begin{array}{r}-0.057 \\
0.522 \\
129 \\
\end{array}$ & $\begin{array}{r}-0.013 \\
0.88 \\
129 \\
\end{array}$ & $\begin{array}{r}-.186^{\star} \\
0.034 \\
129 \\
\end{array}$ & $\begin{array}{r}-0.04 \\
0.654 \\
129\end{array}$ & $\begin{array}{r}-0.145 \\
0.102 \\
129 \\
\end{array}$ & \\
\hline $\mathrm{CO} 2 / \mathrm{CH} 4$ & $\begin{array}{l}\text { Pearson Correlation } \\
\text { Sig. (2-tailed) } \\
\mathrm{N}\end{array}$ & $\begin{array}{r}.182^{\star} \\
0.039 \\
129\end{array}$ & $\begin{array}{r}-0.005 \\
0.953 \\
129\end{array}$ & $\begin{array}{r}.264^{\star *} \\
0.003 \\
129 \\
\end{array}$ & $\begin{array}{r}.267^{\star \star} \\
0.002 \\
129\end{array}$ & $\begin{array}{r}-.384^{* *} \\
0 \\
129\end{array}$ & $\begin{array}{r}.431^{* *} \\
0 \\
129\end{array}$ \\
\hline
\end{tabular}

Correlation is significant at the 0.05 level (2-tailed).

**. Correlation is significant at the 0.01 level (2-tailed).

Macrocosm $=$ M1 


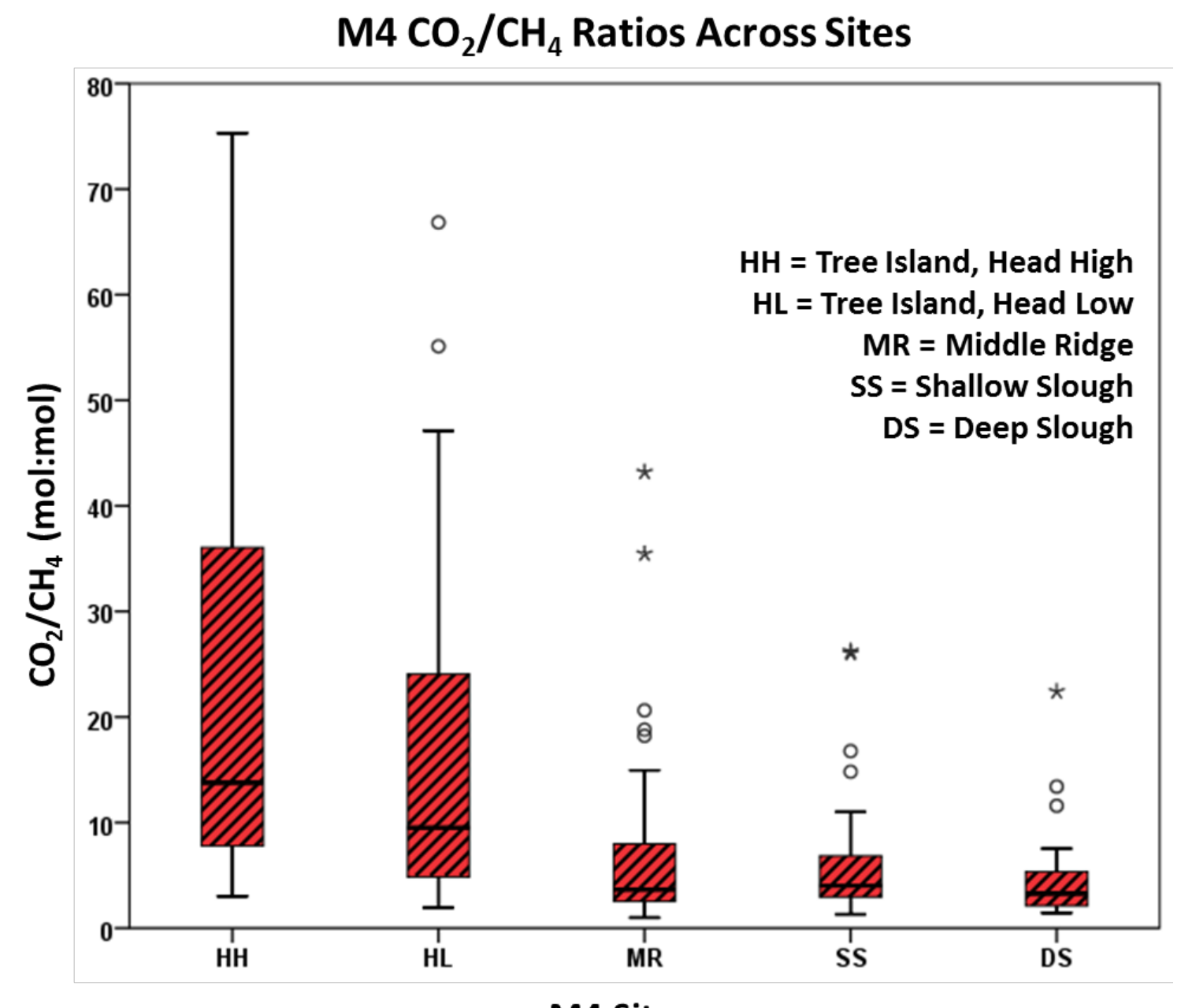

M4 Sites

Figure 15. Boxplot of $\mathrm{CO}_{2} / \mathrm{CH}_{4}$ ratios (mol:mol) taken from pore-water data in $\mathrm{M} 4$ across all sites (HH, HL, MR, SS, and DS), and listed left-to-right from highest to lowest site elevation (except for the HL and MR sites at the same elevation). Circles outside of box-and-whisker plots represent outliers, while stars represent extreme outliers. 


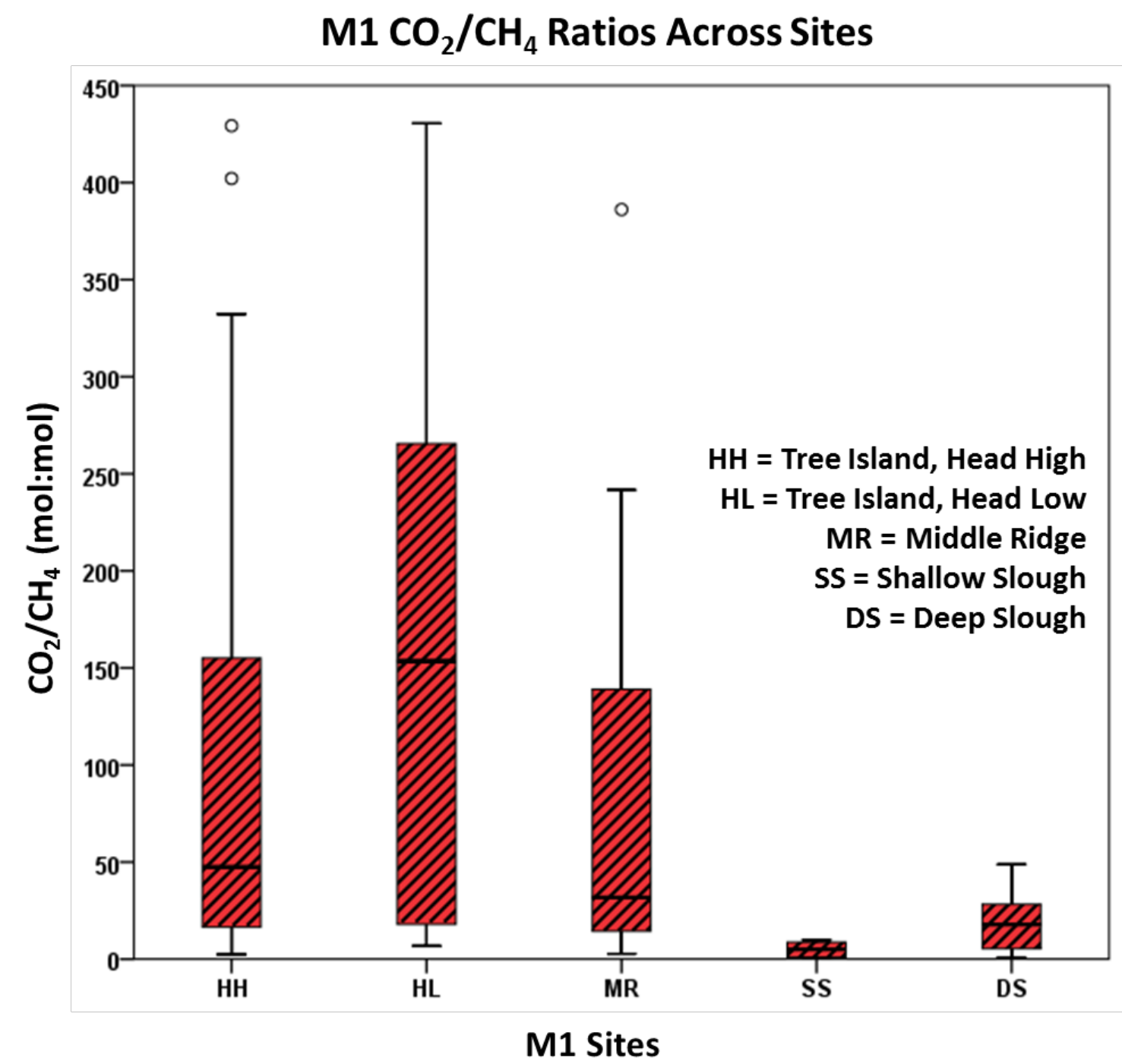

Figure 16. Boxplot of $\mathrm{CO}_{2} / \mathrm{CH}_{4}$ ratios from sipper data across all sites in $\mathrm{M} 1 \mathrm{HH}, \mathrm{HL}$, MR, SS, DS), listed left-to-right from highest to lowest site elevation (except for HL and $\mathrm{MR})$. Circles outside plots represent outliers, stars represent extreme outliers. 
M4 Average $\mathrm{CO}_{2}$ Efflux Rate by Site and Date

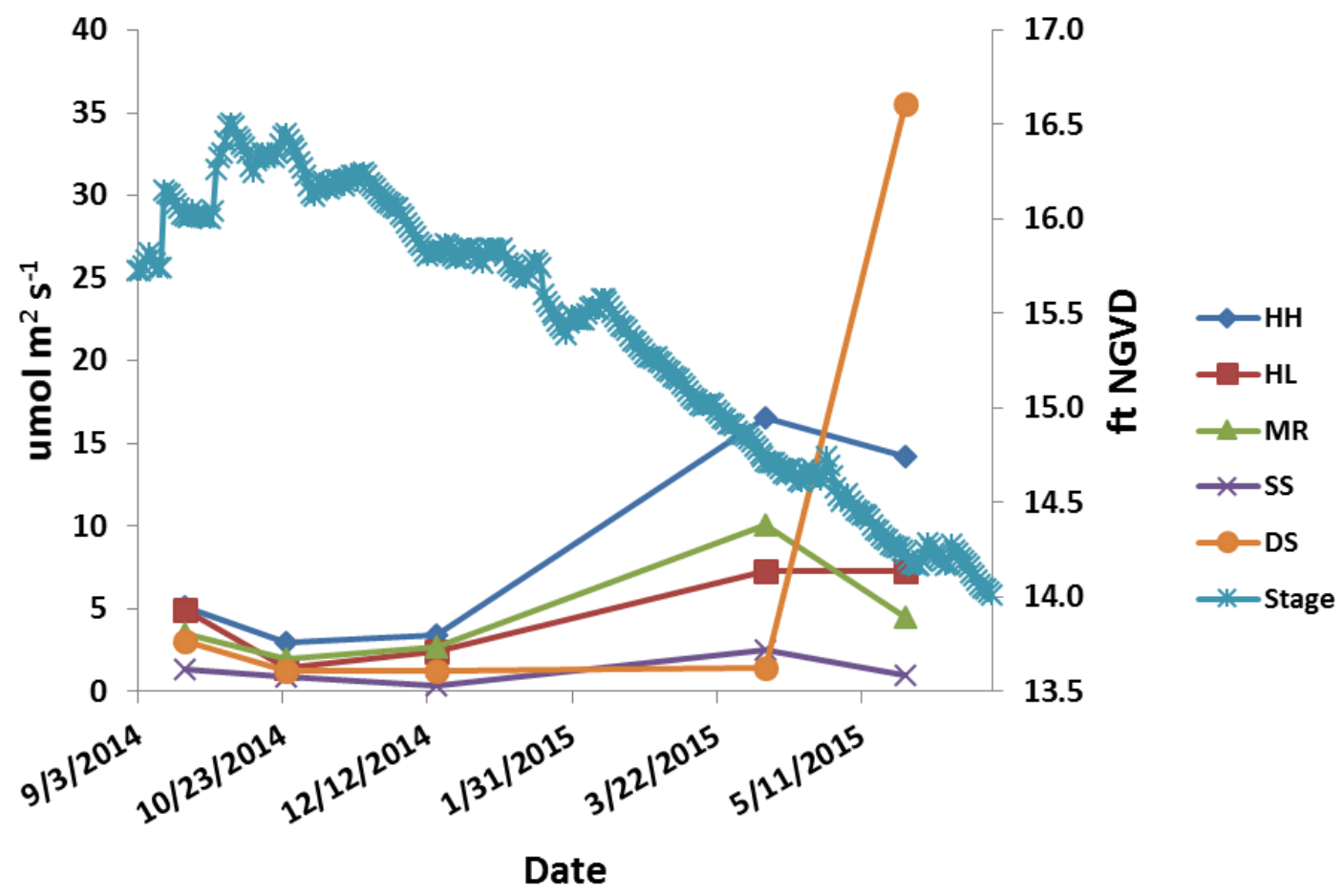

Figure 17. Average LICOR CO 2 efflux rates $\left(\mathrm{mol} \mathrm{m}^{2} \mathrm{~s}^{-1}\right.$ ) across all sites in M4 (HH, HL, MR, SS, DS), with stage values given in ft NGVD, from September 2014 until May 2015. 
M1 Average $\mathrm{CO}_{2}$ Efflux Rate by Site and Date

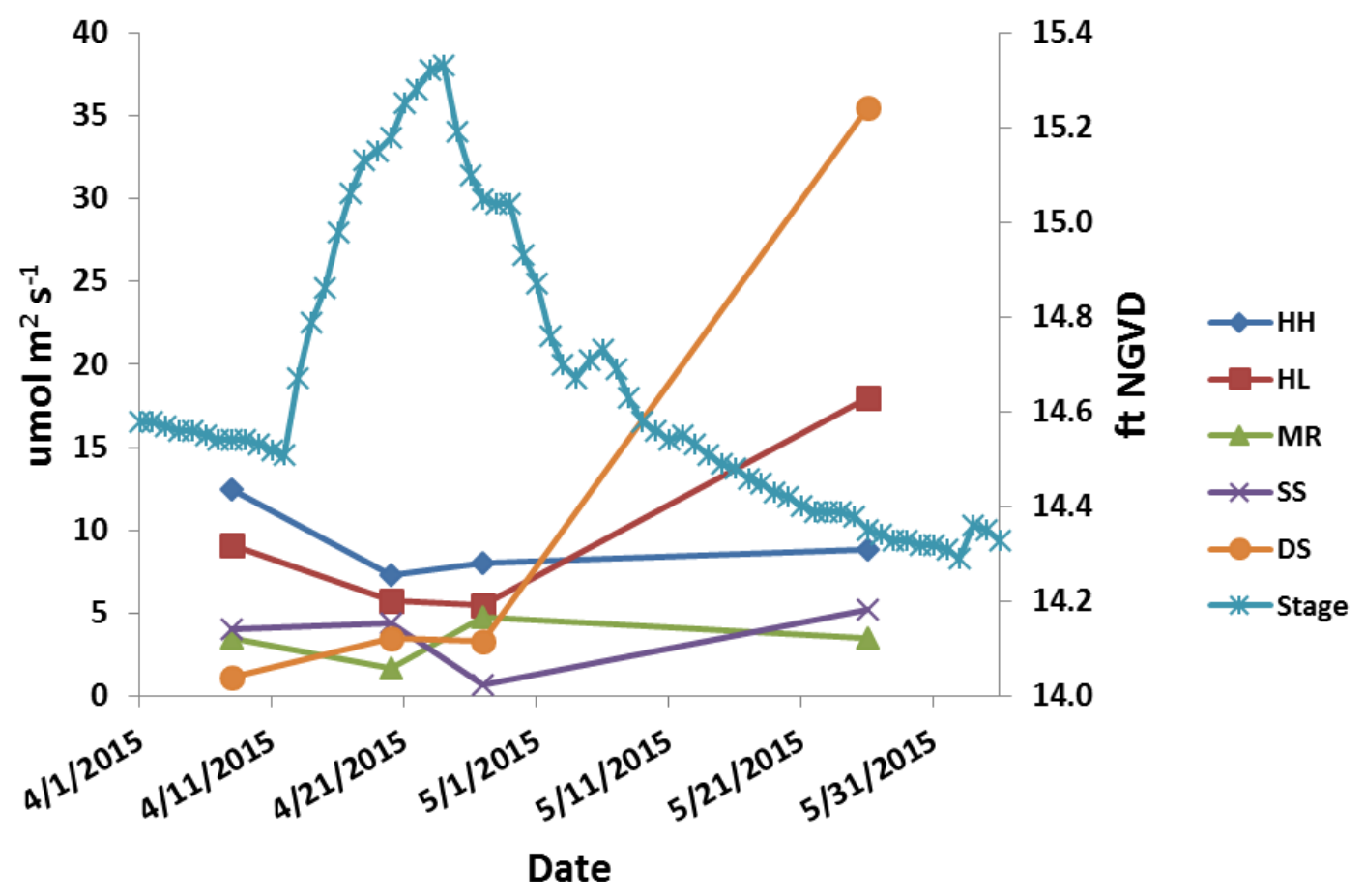

Figure 18. Average LICOR $\mathrm{CO}_{2}$ efflux rates, in $\mathrm{mol} \mathrm{m}^{2} \mathrm{~s}^{-1}$, during $\mathrm{M} 1$ reversal from April 2015 until June 2015, with stage values also given in feet NGVD. 


\section{All Gas Trap Data}

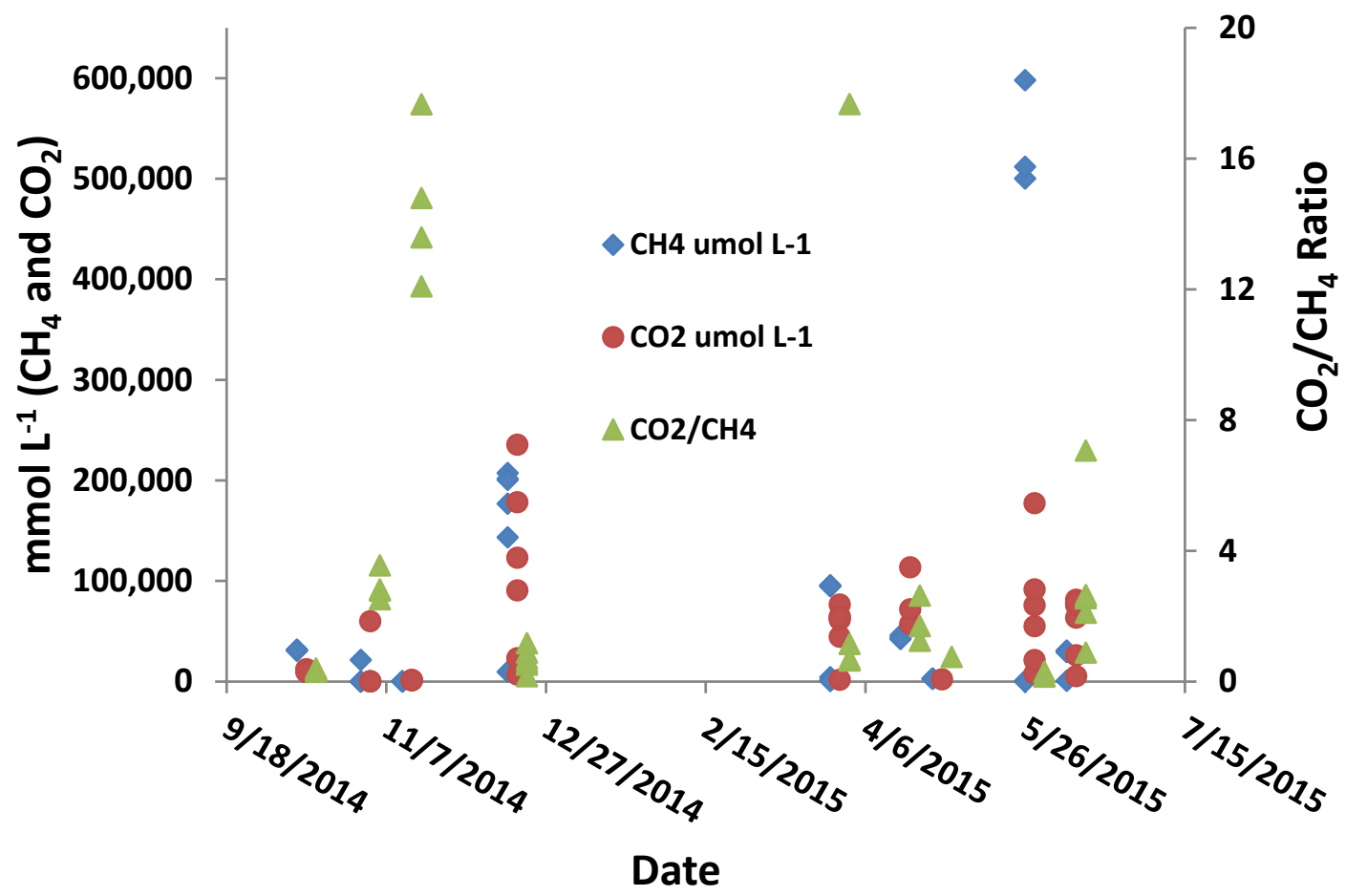

Figure 19. All gas trap data taken from all sites in both macrocosms, from September 2014 until June 2015, with $\mathrm{CH}_{4}$ and $\mathrm{CO}_{2}$ concentrations given in $\mathrm{mmol} \mathrm{L}^{-1}$. 


\section{M4 Gas Traps by Site}

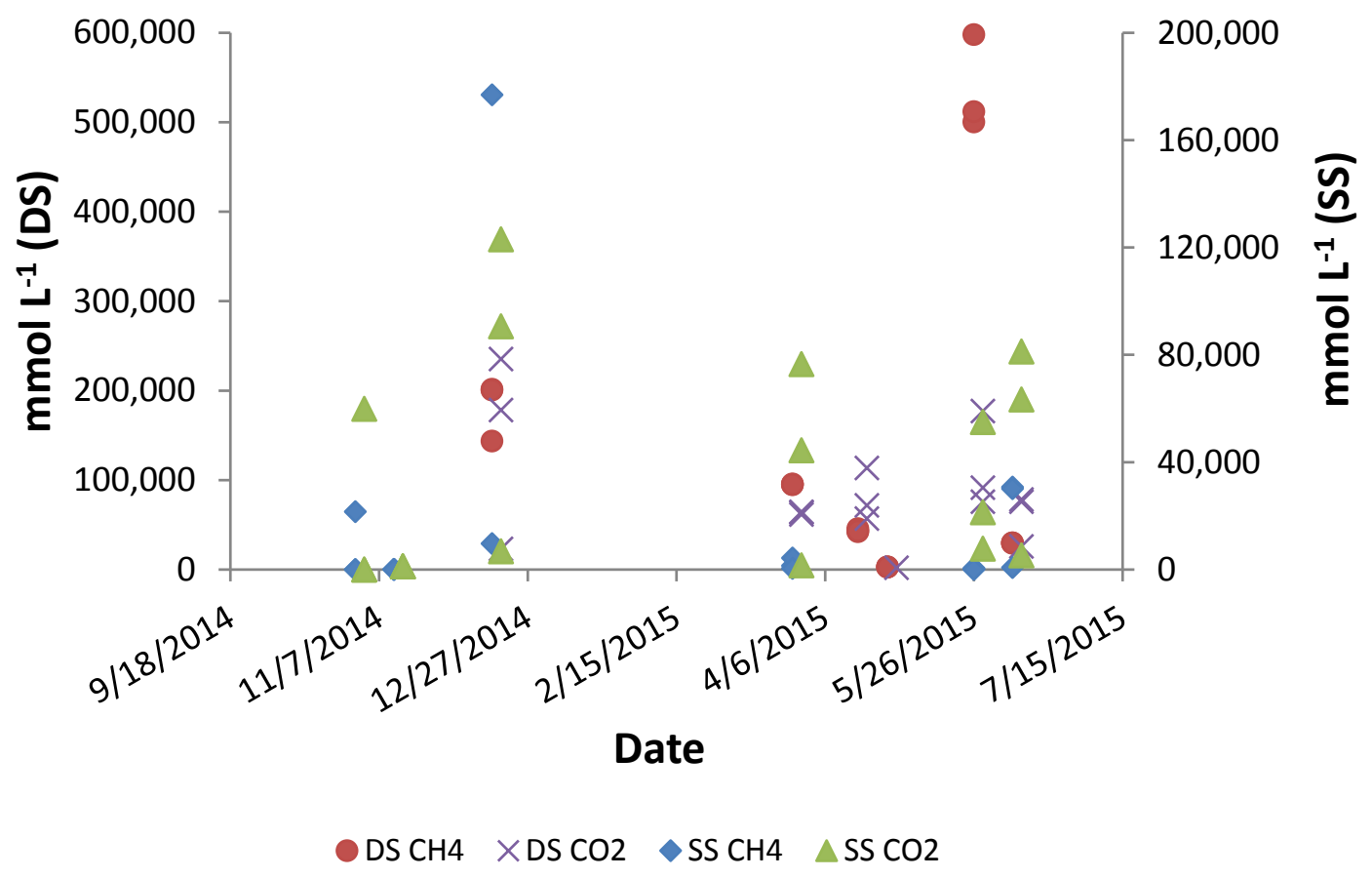

Figure 20. Gas trap data taken from slough sites (DS and SS) in M4, from October 2014 until June 2015, with concentrations of $\mathrm{CH}_{4}$ and $\mathrm{CO}_{2}$ given in $\mathrm{mmol} \mathrm{L}^{-1}$. 